Portland State University

PDXScholar

Spring 7-8-2016

\title{
BEE CAUSE: Is Legislative Action Protecting Bees from Neonicotinoids Justified?
}

Ursula A. Squire

Portland State University

Follow this and additional works at: https://pdxscholar.library.pdx.edu/open_access_etds

Part of the Political Science Commons

Let us know how access to this document benefits you.

\section{Recommended Citation}

Squire, Ursula A., "BEE CAUSE: Is Legislative Action Protecting Bees from Neonicotinoids Justified?" (2016). Dissertations and Theses. Paper 2988.

https://doi.org/10.15760/etd.2989

This Thesis is brought to you for free and open access. It has been accepted for inclusion in Dissertations and Theses by an authorized administrator of PDXScholar. Please contact us if we can make this document more accessible: pdxscholar@pdx.edu. 
BEE CAUSE: Is Legislative Action Protecting Bees from Neonicotinoids Justified?

by

Ursula A. Squire

Submitted in partial fulfillment of the requirements for the degree of

\author{
Master of Science \\ in \\ Political Science
}

Thesis Committee:

Christopher Shortell, Chair Joshua Eastin

Rachel Sanders

\author{
Portland State University \\ 2016
}


(C) 2016 Ursula A. Squire 


\begin{abstract}
The potential harm caused to bees and other pollinators by the widespread use of neonicotinoids has the capacity to pose a real and immediate threat to both the environment and humans. The benefits that bees and other pollinators provide, combined with the potential of harm they may face, are important enough to warrant a more comprehensive testing apparatus by which to evaluate threats to their population. Environmentally, bees and other pollinators are an important piece of ecosystemic balance - from pest management to pollination of plants that are a part of many species' diet. Anthropologically speaking, the way of life humans have been accustomed to and even need in order to survive is also largely dependent on a healthy population of bees and other pollinators; up to $70 \%$ of plants and vegetables we eat are directly a result of pollinators, and one third of every mouthful humans consume is attributed to pollinators. Without a healthy population of pollinators, the agricultural variety and nutritional availability would drastically decrease. Moreover, these agricultural products pollinators are responsible for also affect billions of dollars on both a national and global level. ${ }^{1}$ In many ways, the economic stability of the United States is at an equal risk as the pollinators. For example, an inability to produce many of our own agricultural staples would leave local and regional livelihoods disrupted and change the United States' import/export position. Moreover, this is not just a national problem. Pollinators are responsible for
\end{abstract}

${ }^{1}$ Trumble, John T. "The Dependence of Crops for Pollinators and the Economic Value of Pollination in Brazil." Journal of Economic Entomology, May 4, 2015. 
over 150 billion dollars globally in agriculture. ${ }^{2}$ Many of the nutrients humans need to be healthy would be in short supply.

While scientists continue to study the possible effects of neonicotinoids on pollinators, how should policy makers respond? In this thesis, I argue that the various and drastic ways in which pollinators impact our environment and every day life, combined with the potential of the harsh threats their collapse would entail, warrant a more stringent approach to the evaluation of potential harms like neonicotinoids. An ethical risk assessment, as I define one, would be an appropriate tool to apply to this situation to guide policy makers in drafting regulations even in the absence of scientific certainty. Ethical risk assessments are a tool by which to evaluate the moral and ethical responsibilities in a whole host of different scenarios, one of which is neonics and pollinators. In other words, this ethical risk assessment will be used as an instrument by which to determine whether or not there is a sufficient risk to the population of pollinators, thus determining whether regulation is appropriate. Through application of this risk assessment, I will show that in this particular case regulation is appropriate due to the risks neonics pose to pollinators in light of the evidence that we do have.

\footnotetext{
${ }^{2}$ Gallai, Nicola, Jean-Michel Salles, Josef Settele, and Bernard E. Vaissiere. "Economic Valuation of the Vulnerability of World Agriculture Confronted with Pollinator Decline." Ecological Economics 68, no. 3 (January 15, 2009): 810-21.
} 
I develop a set of criteria for an ethical risk assessment. The criteria are a result of a combination of existing literature and some novel connections I draw here. This list, I argue, is what constitutes an ethical risk assessment. Ethical risk assessment, grounded in Utility Theory, is appropriate here because of its calculative apparatus and sociopolitical applicability. 


\section{DEDICATION}

To my father. Thank you for teaching me how to navigate the wilderness and life.

To my mother. Thank you for always believing in me, and teaching me the importance of following my own path.

To my brother. Thank you for your enthusiasm and friendship. 


\section{ACKNOWLEDGEMENTS}

I would first like to thank my thesis advisor, Dr. Christopher Shortell, Associate Professor of Political Science at Portland State University, for his guidance throughout the research and writing of this thesis. I have been so lucky for the continuous support, patience, and immense knowledge that Dr. Shortell has provided throughout this thesis. Thank you for playing such an influential role in my academic development.

I would also like to thank the professors on my thesis defense committee, Dr. Joshua Eastin, Assistant Professor of Political Science at Portland State University, and Dr. Rachel Sanders, Assistant Professor of Political Science at Portland State University, for their participation and contribution to the defense and final product of this thesis. Thank you for your sincere efforts to make this work the best it can be.

I must express the utmost gratitude to my parents, John Squire and Karen Squire, to my brother Jack Squire, and to my boyfriend, Forester Tesche, for their unwavering support through not only my thesis project, but also my academic career that has led to this point. And to my whole family, who have always been involved in my personal and academic growth. Thank you for always believing in me. Thank you to my amazing friends who have always been there to listen, proofread, and provide constant encouragement. 
Finally, I would like to thank the Political Science Department at Portland State University for the comradery and unwavering support. I thank each of you for contributing to the environment that shaped my amazing experience at Portland State University. 


\section{TABLE OF CONTENTS}

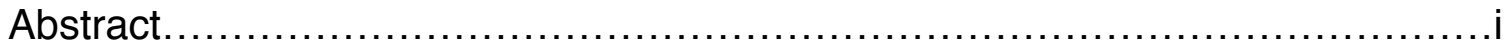

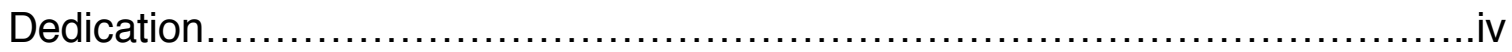

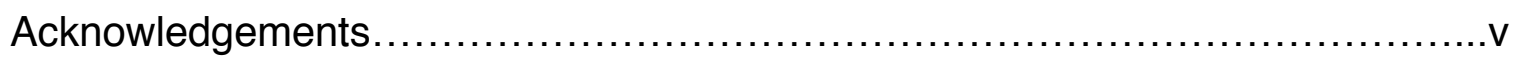

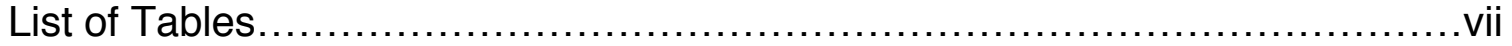

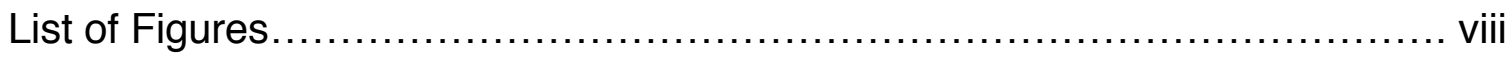

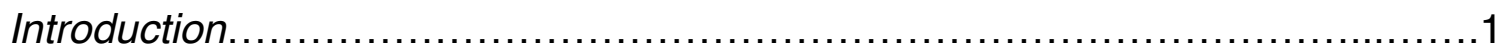

Chapter 1:

Utilitarianism and an Ethical Risk

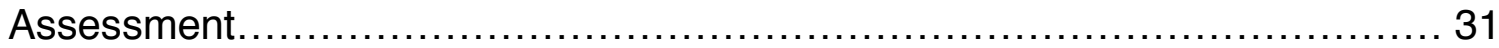

Chapter 2:

Performing an Ethical Risk

Assessment.............................................................. 54

Chapter 3:

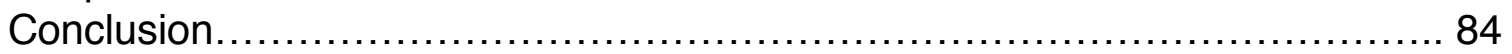

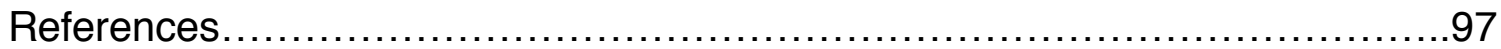

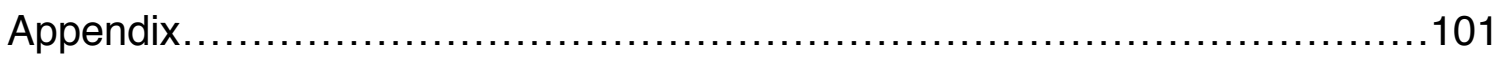




\section{LIST OF TABLES}

\section{Table 1}

Data for Informing EPA's Pesticide Risk Assessment Process for Bees.........57 


\section{LIST OF FIGURES}

Figure 1

Population of Pollinators............................................... 3 


\section{PREFACE}

The selection of this topic was motivated by two primary causes. The first is the interest to do more just than understand the world around me - the interest to protect it. The second motivation is based on the intrinsic relationship between living beings and the environment - a viewpoint instilled in me at a young age. Agriculturally and economically, we rely on pollinators to provide the world with an enormous amount of labor that results in agricultural production and variation. Currently, we spray now and ask questions later. This method concerns me, and I think it not only interesting but also necessary to shed the light of the ethics of risk assessment on this issue. This is a political call to action for the environment. I believe that political science does not play enough of a role in environmental issues and that is an integral tool that must be used in order to implement any significant environmental policy.

The second reason that I selected this topic for my thesis is more personal in nature: my father is a local beekeeper (and all things nature aficionado) in a small town in Colorado. From a very young age it was instilled in me that all things in nature are connected, and as such each element of nature is of equal importance to maintaining ecosystemic balance and longevity. Spending my whole life watching the bees and the care with which they worked made this a personal issue for me and increased the importance I know the issue deserves. I was very lucky to be exposed to the level of natural interconnectedness at such a 
young age, and I hope to share that experience here, as that is the primary undertone of this thesis.

My goal in this thesis is to establish the context of the world in which we live. Humans are a part of the environment, and so harm done to the environment can result in harm to humans' as well. I also aim to demonstrate that this view does not have to only be understood as in stark contrast to the world we live in today; but that a marrying of politics and environmental consciousness can produce desirable results without forgoing all of our modern amenities. Through a more thorough approach toward policy by application of an ethical risk assessment, we are better equipped to make policy that protects the earth and ourselves. Understanding the direct link between the health of the environment and the economic, social, and agricultural impacts on humans is crucial to understanding this thesis and vital to implementing meaningful change in the world today. 
"The bees are the life guarantors of nature itself, so we have to try to take care of them. By taking care of them, we take care of ourselves." - Gunther Hauk, Holistic Bee Farmer

\section{INTRODUCTION}

In 2006, the western honeybee (Apis mellifera) began a markedly rapid decline.

${ }^{3}$ While evidence of the cause(s) of this decline remains inconclusive, the consequences of a decline continuing at this rate could prove to be irreparable. Contributions from bees and other pollinators include agricultural variety (along with the nutritional value this provides) and economic stability. It is estimated that approximately one in three mouthfuls of food are attributed to bees and other pollinators. ${ }^{4}$ Economically, pollinators are responsible for over $\$ 150$ billion globally in agriculture, with over $70 \%$ of food sources in the United States dependent on pollinators. ${ }^{5}$ Honeybees and other pollinators are also a crucial element in retaining ecosystemic balances, like pollination, "Beyond agriculture, pollinators are keystone species in most terrestrial ecosystems: they pollinate the seeds and fruits that feed everything from songbirds to grizzly bears. Thus,

\footnotetext{
${ }^{3}$ Bailes, Emily J., Jeff Ollerton, Jonathan G. Pattrick, and Beverly J. Glover. "How Can an Understanding of Plant-Pollinator Interactions Contribute to Global Food Security." Current Opinion in Plant Biology 26 (August 2015): 72-79. http://www.sciencedirect.com.proxy.lib.pdx.edu/science/article/pii/S1369526615000849.

${ }^{4}$ Kaplan, Kim. "Honey Bee Health and Colony Collapse Disorder." USDA. Accessed September 15, 2015. http://www.ars.usda.gov/News/docs.htm?docid=15572\#public.

${ }^{5}$ Miller, G. Tyler, and Scott Spoolman. Sustaining the Earth. 11th ed. N.p.: Cengage Learning, 2013. 97.
} 
conservation of pollinating insects is critically important to preserving both wider biodiversity and agriculture."6

The decrease of the bee population in the United States is now quantifiable to a more precise degree, and the figures are enormous. Since 1947 we have lost over half of our domestic/commercial bee population, from 6 million in 1947 to 2.5 million today. ${ }^{7}$ According to a recent study, the agricultural community is already drastically feeling the effects. From $2005-2010$, the demand for bees for pollination grew 4.9 times faster than the population of bees needed for pollination throughout Europe and the U.S. ${ }^{8}$ Since 1961, the land in the U.S. devoted to growing crops that depend on pollinators has increased by $300 \%$, while the population of bees has dropped by about $50 \%$. The effects thus far have been mitigated by wild bees and other pollinators working over time. However, it is unrealistic to rely on this as a method for sustainability in the long run. Further, it is impossible to know how long wild pollinators' overtime is even a feasible option, as that type of data is just simply not available to collect. Below is a map to demonstrate the population of pollinators and the effects on specific countries.

\footnotetext{
${ }^{6}$ Hopwood, Jennifer et. al. "Are Neonicotinoids Killing Bees?." Xerces Society. Accessed November 17, 2015. http://ento.psu.edu/publications/are-neonicotinoids-killing-bees.

${ }^{7}$ USDA 2012 Report on the National Stakeholders Conference on Honey Bee Health. October 15-17,2012.

${ }^{8}$ Breeze, Tom D., Bernard E. Vaissière, Riccardo Bommarco, Theodora Petanidou, Nicos Seraphides, Lajos Kozák, Jeroen Scheper, Jacobus C. Biesmeijer, David Kleijn, Steen Gyldenkærne, Marco Moretti, Andrea Holzschuh, Ingolf Steffan-Dewenter, Jane C. Stout, Meelis Pärtel, Martin Zobel, and Simon G. Potts. "Agricultural Policies Exacerbate Honeybee Pollination Service Supply-Demand Mismatches Across Europe." PLOS ONE 9, no. 1 (2014).
} 
Figure 1: Population of Pollinators
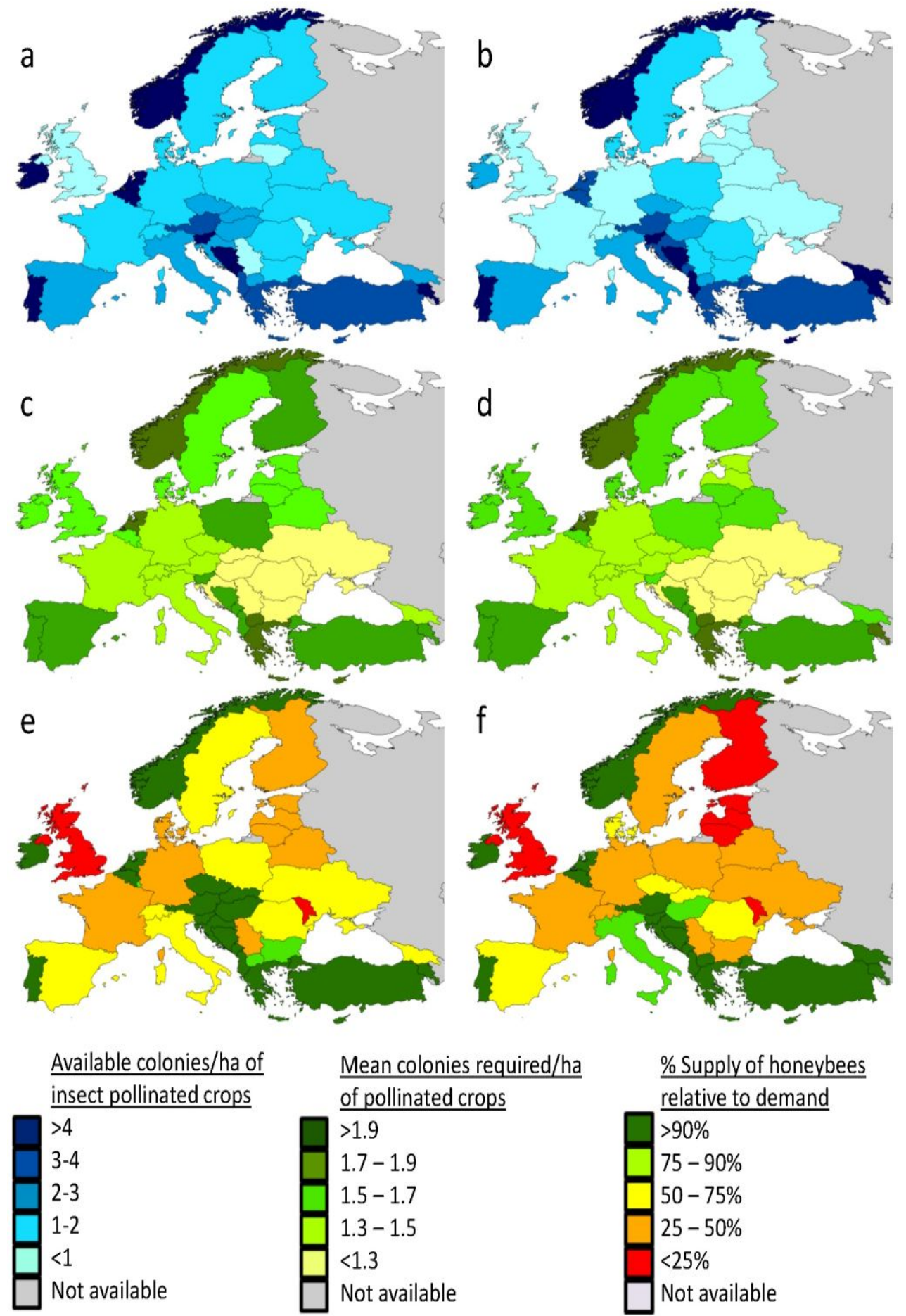

${ }^{9}$ Breeze, Tom D., Bernard E. Vaissière, Riccardo Bommarco, Theodora Petanidou, Nicos
Seraphides, Lajos Kozák, Jeroen Scheper, Jacobus C. Biesmeijer, David Kleijn, Steen Seraphides, Lajos Kozák, Jeroen Scheper, Jacobus C. Biesmeijer, David Kleijn, Steen 
The impacts of a rapidly declining pollinator population have become an issue for both the general public and for policy makers. While the evidence remains inconclusive for the exact cause of this rapid decline of pollinator population, many policymakers argue there is enough evidence that neonicotinoid pesticides are the primary culprits. Policies that concern evidentiary uncertainty or ambiguity that also have the potential to have drastic effects on important factors like economic stability and agricultural variation ought to err on the side of caution. Several cities have adopted this approach, which will be discussed later in this section. But is this legislative action justified? In this thesis I argue that the benefits of pollinators on the environment and thus human life demand a more rigorous set of criteria by which to evaluate policymaking, particularly in the face of evidentiary uncertainty. To perform this evaluation, I argue that an ethical risk assessment ought to be used. In chapter 2 I develop a set of criteria that constitute this ethical risk assessment, along with a more in-depth discussion of these issues.

Gyldenkærne, Marco Moretti, Andrea Holzschuh, Ingolf Steffan-Dewenter, Jane C. Stout, Meelis Pärtel, Martin Zobel, and Simon G. Potts. "Agricultural Policies Exacerbate Honeybee Pollination Service Supply-Demand Mismatches Across Europe." PLoS ONE 9, no. 1 (2014). 


\section{Colony Collapse Disorder (CCD) - What Is It?}

Researchers, farmers, and others interested in the bee decline labeled the hazard Colony Collapse Disorder to describe the drastic population decline in honeybees. Colony Collapse Disorder (CCD) is a threat that has been increasingly affecting honeybees, particularly the western honeybee. CCD is characterized by the absence of the majority of worker bees in a hive, while a healthy queen, immature bees, nurse bees, and food supplies are maintained in the hive. This means that lack of food, worker bees, etc. are not the cause of the hive's abandonment.

In an attempt to remove the ambiguity surrounding CCD, U.S. bee scientists defined some of the symptoms often associated with the phenomenon. In collapsed (dead) colonies, CCD may produce the following symptoms: 1 . the complete absence of adult bees in colonies with few or no dead bees in / around colonies; 2. The presence of capped brood; and 3. The presence of food stores that are not robbed by other bees or typical colony pests. CCD symptoms often associated with collapsing (weakening) colonies may include: 1. an insufficient number of bees to maintain the amount of brood in the colony; 2 . the workforce is composed largely of younger adult bees; 3 . the queen is present; and 4 . the cluster of bees is reluctant to consume food provided to them by the beekeeper. ${ }^{10}$

\footnotetext{
${ }^{10}$ James D. Ellis, Jay D. Evans \& Jeff Pettis (2010) Colony losses, managed colony population decline, and Colony Collapse Disorder in the United States, Journal of Apicultural Research, 49:1, 134-136
} 
However, the 'missing' bees are also nowhere to be found near the hive. In fact, cases of CCD do not result in a large finding of a hive's bees... they are essentially lost.

The cause of CCD remains inconclusive, though there are theories that waft through the agricultural and entomological communities. ${ }^{11}$ There are various factors that are thought to have an impact on bees' population, including mites, lack of nutrition, disappearing habitat, and use of systemic pesticides like neonicotinoids. ${ }^{12}$

CCD started to become alarmingly noticeable in 2006, and since then bee colonies have been collapsing at even more rapid rates. This risk threatens bees and humans alike - from well-being and nutrition, to agricultural variation and economic stability. The USDA released a report from their study on bee population and the effects of CCD, and had some dire warnings,

If losses continue at the 33 percent level, it could threaten the economic viability of the bee pollination industry. Honeybees would not disappear entirely, but the cost of honeybee pollination services would rise, and those increased costs would ultimately be passed on to consumers through higher food costs. Now is the time for research into the cause and treatment of CCD before CCD becomes an agricultural crisis. ${ }^{13}$

${ }^{11}$ vanEngelsdorp, Dennis et. al. "Colony Collapse Disorder: A Descriptive Study." PLOS One (August 2009). Accessed October 7, 2015.

http://journals.plos.org/plosone/article?id=10.1371/journal.pone. 0006481 .

${ }^{12}$ Lecture, The Loss of Ecosystem Services as a Result of Colony Collapse Disorder. April 30, 2105. http://digitalcommons.colby.edu/clas/2015/program/26/

${ }^{13}$ Kaplan, Kim. "Honey Bee Health and Colony Collapse Disorder." USDA. Accessed September 15, 2015.http://www.ars.usda.gov/News/docs.htm?docid=15572\#public. 
The Federation of American Scientists, an independent group of academics

and researchers, provides a list of symptoms of CCD:

- $\quad$ Rapid loss of adult worker bees

- $\quad$ Few or no dead bees found in the hive

- $\quad$ Presence of immature bees (brood)

- $\quad$ Small cluster of bees with live queen present

- $\quad$ Pollen and honey stores in hive

Among the key symptoms of CCD in collapsed colonies is that the adult population is suddenly gone without any accumulation of dead bees. The bees are not returning to the hive but are leaving behind their brood (young bees), their queen, and maybe a small cluster of adults. What is uncharacteristic about this situation is that the honeybee is a very social insect and colony-oriented, with a complex and organized nesting colony. Failing to return to the hive is considered highly unusual. An absence of a large number of dead bees makes an analysis of the causes of CCD difficult. Also, there is little evidence that the hive may have been attacked. In actively collapsing colonies, an insufficient number of adult bees remain to care for the brood. The remaining workforce seems to be made up of young adult bees. The queen is present, appears healthy, and is usually still laying eggs, but the remaining cluster is reluctant to consume feed provided by the beekeeper, and foraging is greatly reduced. ${ }^{14}$

From 2006 to 2013, CCD was responsible for the collapse of some ten million

beehives. ${ }^{15}$ Normal rates of loss for a beehive are around $10-30 \%$ annually. But

${ }^{14}$ Johnson, Renee. "Honey Bee Colony Collapse Disorder." Federation of American Scientists. (January 7 2010) 8. https://fas.org/sgp/crs/misc/RL33938.pdf.

${ }^{15}$ Walsh, Bryan. "Beepocalypse Redux: Honeybees Are Still Dying - and We Still Don't Know Why." Time Magazine, May 7, 2013 http://science.time.com/2013/05/07/beepocalypseredux-honey-bees-are-still-dying-and-we-still-dont-know-why/. 
since 2006, beekeepers have noticed decreases up to $90 \% .{ }^{16} 2015$ was a

particularly disastrous year, with losses averaging $42 \%$ (the highest annual loss average) ${ }^{17}$ CCD has seriously affected at least 35 states since $2006 .{ }^{18}$

These statistics portray drastic effects on the population of pollinators locally and globally.

The National Resources Council of the National Academies is another independent scholarly group that evaluates various issues in the country, including CCD. They released a several hundred-page manuscript on the status of honeybees in North America, and they begin with highlighting the importance of honeybees,

\begin{abstract}
About three-quarters of the more than 240,000 species of the world's flowering plants rely on pollinators-insects, birds, bats, and other animals - to various degrees to carry pollen from the male to the female parts of flowers for reproduction. Pollinators are vital to agriculture because most fruit, vegetable, seed crops and other crops that provide fiber, drugs, and fuel are pollinated by animals. Beepollinated forage and hay crops, such as alfalfa and clover, also are used to feed the animals that supply meat and dairy products. Animal-pollinated crops generally provide relatively higher income to growers than do crops pollinated in other ways.
\end{abstract}

\footnotetext{
${ }^{16}$ Walsh, Bryan. "Beepocalypse Redux: Honeybees Are Still Dying - and We Still Don't Know Why." Time Magazine, May 7, 2013 http://science.time.com/2013/05/07/beepocalypseredux-honey-bees-are-still-dying-and-we-still-dont-know-why/.

${ }^{17}$ Wines, Michael. "Mystery Malady Kills More Bees, Heightening Worry on Farms." New York Times, March 28, 2013. http://www.nytimes.com/2013/03/29/science/earth/soaring-beedeaths-in-2012-sound-alarm-onmalady.html?hp\&utm_source=buffer\&buffer_share=7418a\&_r=1.

${ }^{18}$ National Research Council, "Status of Pollinators in North America," The National Academies Press, Washington, D.C., 2007, www.nap.edu/catalog/11761/status-of- pollinators-innorth-america; Holden, C., "Report warns of looming pollination crisis in North America," Science, 314, pp. 397, October 20, 2006, www.sciencemag.org/ content/314/5798/397.
} 
Over and above its direct economic value to humans, pollination by animals provides essential maintenance of the structure and function of a wide range of natural communities in North America, and it enhances aesthetic, recreational, and cultural aspects of human activity. In view of that economic and ecological importance, this report assesses the status of pollinators in North America, identifies species for which there is evidence of decline, analyzes the putative causes of those declines, and discusses their potential consequences. ${ }^{19}$

These reports, combined with the enormous contributions bees and other pollinators make to ecosystemic longevity, economic stability, and agricultural variation make it imperative that their rapid decline be explored further, and the causes evaluated more precisely.

One such cause of CCD and the decline of pollinators' population that has been increasingly suggested in the past decade are neonicotinoids (neonics), a systemic pesticide used in agricultural practices. In the next section, I will explore neonics in more detail.

19 "Summary." National Research Council. Status of Pollinators in North America. Washington, DC: The National Academies Press, 2007. 


\section{Neonicotinoids - What Are They?}

Neonicotinoids are a type of systemic pesticide that have been increasingly applied to farms, gardens, and public lands like school yards. Neonicotinoids now make up about $25 \%$ of the pesticide market, making them the most common insecticide currently used, ${ }^{20}$ and are licensed in over 120 countries. ${ }^{21} \mathrm{~A}$ systemic pesticide means that the pesticide is absorbed into the plant's whole physical infrastructure. Systemic pesticides differ from topical pesticides in that they do not only perform on the leaves and/or surfaces they are directly applied to; instead, with systemic pesticides, the effects are manifested throughout the whole physical infrastructure of the plant. This 'systemic' absorption and manifestation has, in many ways, revolutionized agricultural practices around the world. The success of neonics in part depends on their ability to be so effective against pests that have developed a resistance to other insecticides. ${ }^{22}$ Another attractive feature of neonics is that the application of a systemic pesticide can require much less precision (as the chemicals can be absorbed into the plant infrastructure via methods like seed soaking), and there are many

\footnotetext{
${ }^{20}$ van der Sluijs, Jeroen P., Noa Simon-Delso, Dave Goulson, Laura Maxim, Jean-Marc Bonmatin, and Luc P. Belzunces. "Neonicotinoids, Bee Disorders and the Sustainability of Pollinator Services." Current Opinion in Environmental Sustainability 5, no. 3-4 (September 2013): 293-305.

${ }^{21}$ Goulson, Dave. "REVIEW: An overview of the environmental risks posed by neonicotinoid insecticides." Journal of Applied Ecology 50, no. 4 (June 13, 2013): 977-87.

${ }^{22}$ Elbert, Alfred et. al. "Applied aspects of neonicotinoid uses in crop protection." Pest Management Science 64, no. 11: 1099-105.
} 
more ways neonics can be applied. ${ }^{23}$ Moreover, many consumers and farmers alike are able to purchase plants or seeds that have already been treated by neonics. Often, seeds are soaked in the pesticide agent and the effects spread through the plant as it grows. This convenience has had a huge impact on the modern agricultural world with the most commonly used pesticide in the United States being neonics, with annual crop application estimations hovering around 150 million acres. ${ }^{24}$. Using neonics is extremely convenient and cost effective, especially in the era of monocultures, which are particularly susceptible to pest infestation and spreading.

Along with the benefits of neonicotinoids come questions about the impact on the environment surrounding their application. For example, the neonics often spread into surrounding soil ${ }^{25}$. Moreover, since neonics affect the entire apparatus of the plant, many scientists, beekeepers, and researchers have questioned where the effects stop; neonicotinoids are manifested in the whole apparatus of the plant including the blooming mechanisms. So, it is questioned, are these effects passed onto pollinators that collect the pollen and nectar of plants to which neonics have been applied? Moreover, given the duration that neonics are effective, do the chemicals stay in the soil and

\footnotetext{
${ }^{23}$ Elbert, Alfred et. al. "Applied aspects of neonicotinoid uses in crop protection." Pest Management Science 64, no. 11: 1099-105.

${ }^{24}$ LaJeunesse, Sara. "Rapid increase in neonicotinoid insecticides driven by seed treatments." Penn State News, April 2, 2015. http://news.psu.edu/story/351027/2015/04/02/research/rapid-increase-neonicotinoidinsecticides-driven-seed-treatments.

${ }^{25}$ Goulson, Dave. "REVIEW: An overview of the environmental risks posed by neonicotinoid insecticides." Journal of Applied Ecology 50, no. 4 (June 13, 2013): 977-87.
} 
systems of pollinators for the same amount of time that they are retained in plants? Moreover, to what extent are the concentrations regulated in the consumer market?

While the effects of neonicotinoids on pollinators is considered inconclusive, evidence does suggest that there is at least some level of harm caused to pollinators by the use of neonicotinoids. The effects can be anything from chronic to lethal, depending on the dosage. Even long durations of nonlethal exposure can have detrimental effects on the health of pollinators. ${ }^{26}$ The problem extends beyond simply bees dropping dead at their hives; sublethal effects include disrupted digestive systems, impaired navigational apparatuses, nerve and neurological damage, and immune deficiencies. ${ }^{27} T h e$ disrupted digestive systems and immune deficiencies leave bees and other pollinators unarmed against diseases and predators like the Varroa mite to which they are normally immune. Impaired navigation confuses the bees and they often cannot find their way back to their hive. ${ }^{28}$

So, how are the effects of pesticides on pollinators tested, measured, and evaluated? In order to register the use of these neonic products for use in

${ }^{26}$ Blacquiere, Tjeerd, Guy Smagghe, Cornelis van Gestel, and Veerle Mommaerts.

"Neonicotinoids in bees: a review on concentrations, side-effects and risk assessment." Ecotoxicology 21, no. 4 (May 2, 2012): 973-92.

${ }^{27}$ Blacquiere, Tjeerd, Guy Smagghe, Cornelis van Gestel, and Veerle Mommaerts. "Neonicotinoids in bees: a review on concentrations, side-effects and risk assessment." Ecotoxicology 21, no. 4 (May 2, 2012): 973-92.

${ }^{28}$ Hopwood, Jennifer et. al. "Are Neonicotinoids Killing Bees?." Xerces Society. Accessed November 17, 2015. http://ento.psu.edu/publications/are-neonicotinoids-killing-bees.; "Neonicotinoids in bees: a review on concentrations, side-effects and risk assessment." Ecotoxicology 21, no. 4 (May 2, 2012): 973-92. 
the United States, the EPA is responsible for conducting an evaluation to determine the potential harm (and extent of the potential harm). The EPA uses a three-tiered system that is used for detecting the toxicity of pesticides. ${ }^{29}$ The EPA tests for lethal dosages and effects of neonics. Though there is not conclusive evidence of the exact cause of CCD or the extent of harm of the use of neonics, there is a consensus among scientists that the potential for harm to pollinators from the use of neonics ought to be evaluated further for two main reasons: First, the application to the plant or seed targets the infrastructure of the plant and becomes absorbed. Because of this, traces of the pesticide are produced into the pollen, nectar, and general blooming apparatus of the flower or plant. ${ }^{30}$ Bees are especially susceptible to these chemicals when they are pollinating. The second reason is that these chemicals attack the system of bees as well. The effect is more than traditional pest management, but is not regarded as such by many chemical companies, or even the EPA, because of the lack of detectable immediate lethal effects. Moreover, there is inconclusive evidence in terms of the immediate or delayed effects, as well as those that are lethal and sublethal. Instead, the effects are sublethal and often take days to

${ }^{29}$ EPA United States Environmental Protection Agency. N.p., n.d. Web. 20 Feb. 2016. $<\mathrm{http}: / /$ www.epa.gov/pesticide-registration/data-requirements>.

${ }^{30}$ Blacquiere, Tjeerd, Guy Smagghe, Cornelis van Gestel, and Veerle Mommaerts. "Neonicotinoids in bees: a review on concentrations, side-effects and risk assessment." Ecotoxicology 21, no. 4 (May 2, 2012): 973-92. ; Demas, A, and K Kuivila. Insecticides Similar to Nicotine Widespread in Midwest. United States Geological Survey, 24 July 2014. Web. 17 Sept. 2017 <http://www.usgs.gov/newsroom/article.asp?ID=3941\#.Vskb3c5Rfww>. 
manifest, through attacking of the nerves, digestive system, and navigational abilities. ${ }^{31}$ These effects are thought to be significant contributing factors as to why the bees are not found dead near the hives, but instead lost on their way home. ${ }^{32}$ The EPA continues to register these products essentially because the conclusive evidence just isn't there that neonics are the cause of these rampant bee deaths. There is a lot of information missing as to the role that neonics play in contributing to $C C D$ and the decline of pollinators.

In the face of this uncertainty of the cause of CCD and whether or not there is a connection to neonics, how should policymakers decide whether something ought to be regulated? In the face of inconclusive evidence like that surrounding neonics and CCD, are there ways to evaluate policymaking? I argue that there are, and that the decision regarding whether or not to apply regulatory policymaking in a given situation ought to be decided via application of an ethical risk assessment.

Based on the potential affects of neonics outlined about (such as spreading in the soil and also becoming absorbed by any pollinator that feeds from the pollen), the use of neonics may affect other areas of the environment, too. Moreover, right now we are spraying first and seeing how the effects play out. In fact, an important point in this thesis is that we do not need to be

${ }^{31}$ Blacquiere, Tjeerd, Guy Smagghe, Cornelis van Gestel, and Veerle Mommaerts.

"Neonicotinoids in bees: a review on concentrations, side-effects and risk assessment." Ecotoxicology 21, no. 4 (May 2, 2012): 973-92.

${ }^{32}$ Dwyer, Marge. "Study strengthens link between neonicotinoids and collapse of honey bee colonies." Harvard School of Public Health. N.p., May 2014. Web. 20 Aug. 2015. $<$ http://www.hsph.harvard.edu/news/press-releases/study-strengthens-link-betweenneonicotinoids-and-collapse-of-honey-bee-colonies/>. 
operating with such a high burden of proof that neonics are not harmful. The burden of proof should rest with the chemical companies to prove the pesticides are not harmful. Moreover, holding such a high standard of proof as to pesticide harm is not consistent with a commitment to moral or ethical behavior. This high standard should not be a requirement, nor the evidentiary threshold that shapes testing frameworks like the one used by the EPA to evaluate neonics. Instead, I argue that in the face of uncertainty, we should apply an ethical risk assessment to determine whether or not regulation is justified. 


\section{Neonicotinoids in Policy}

The recent substantial rise in Colony Collapse Disorder has garnered media and policy attention alike, particularly in the last few years. Many cities and municipalities have heeded the potential warnings of neonicotinoids as the cause, effectively banning their use on public property. In this next section, I will provide a discussion of policy and/or legislative action that has been implemented to ban the use of neonicotinoid pesticides. The cities discussed below are the cities that have implemented these types of policy.

Eugene was the first city in Oregon and in the United States to ban the use of neonicotinoid pesticides in June 2013. Eugene's ban temporarily restricts the use of neonicotinoid pesticides on all city property. The ban was in response to the overall drastic decline in the bee population in Oregon, and specifically to a massive bee die-off during a spraying in a Target parking lot in Wilsonville, Oregon that resulted in the death of some 50,000 bees $^{33}$. Eugene (and other cities who have enacted the ban) stress that while this massive dieoff is concerning, it is by no means the only incident. Proponents of the ban

\footnotetext{
${ }^{33}$ Xerces. 2013. Scientists Call for an End to Cosmetic Insecticide Use After the Largest Bumble Bee Poisoning on Record. The Xerces Society for Invertebrate Conservation. http://www.xerces. org/2013/06/27/scientists-call-for-an-end-to-cosmetic-insecticide-useafter-the-largest-bumble- bee-poisoning-on-record/
} 
argue that it is not only massive sprayings like the one occurring in the Target parking lot in Eugene, but the consistent use of lower level pesticides (personally, publically and commercially) that contain neonicotinoids as well. Vera Krischik, an entomologist at the University of Minnesota, is a prominent voice in this cause. Krischik asserts a connection between neonics and pollinators' decline. She establishes that only 10 parts per billion (ppb) levels induce the impacts onto bees, "research also shows that neonicotinoids can have multiple sublethal effects on bees, including disorientation, effects on learning and a reduction in pollen collection and storage. ${ }^{34}$

In Portland, Oregon, the city council called an emergency vote that called to ban the use of neonicotinoids until further evaluation has been done on their effects on pollinators. The ban was put in place in March 2015. The city council voted unanimously to enact the ban immediately. The ordinance applies to most public land in Portland and also stresses the importance of retailers labeling their products that contain these pesticides. Portland's adoption of the ordinance was motivated by the bee death mentioned earlier that took place in Wilsonville, Oregon when some 50,000 bees died after a massive spraying of neonicotinoids. ${ }^{35}$ Lori Ann Burd, the Director of Environmental Health for the

\footnotetext{
${ }^{34}$ Krischik, Vera. "Protecting bees and beneficial insects from systemic insecticides applied in landscapes." University of Minnesota Extension. University of Minnesota, 24 July 2014. Web. 21 Aug. 2015. <http://www.extension.umn.edu/garden/plant-nurseryhealth/protecting-bees-beneficial-insects-systemic-insecticides/docs/protecting-beesfrom-insecticides.pdf>.

${ }^{35}$ House, Kelly. "Oregon Bans the Use of Bee-Killing Insecticides on Linden Trees." The Oregonian, February 27, 2015.
} 
Center for Biological Diversity explained that it is not just these massive potent sprayings that are harmful to the bees; less potent exposure is just as harmful, "Bees who are exposed to even tiny levels experience hits to the neurological function.... They can't find their way back to the hive, they have less foraging success, they can't communicate effectively, and they can't fight off wasps. Those impacts are really significant on the population scale."36

The massive bee die offs in Oregon, along with the legislation passed in response, sparked the state of Oregon's launch of a statewide task force to look more closely into not only preventative measures for pollinators, but also possible ways to protect them.

Neonics can also potentially be harmful to bees and other pollinators before a spray, as they are often included in nursery plants and seeds. Friends of the Earth, an environmental activist organization, conducted a study to closer examine these effects. This is the first study of its kind, as many studies don't consider the harmfulness level of those plants and seeds labeled as 'beefriendly.' Friends of the Earth's study concluded in part that,

The findings indicate that bee-friendly nursery plants sold at U.S. retailers may contain systemic pesticides at levels that are high enough to cause adverse effects on bees and other pollinators -

http://www.oregonlive.com/environment/index.ssf/2015/02/oregon_bans_use_of_beekilling.html.

${ }^{36}$ House, Kelly. "Oregon Bans the Use of Bee-Killing Insecticides on Linden Trees." The Oregonian, February 27, 2015. http://www.oregonlive.com/environment/index.ssf/2015/02/oregon_bans_use_of_beekilling.html. 
with no warning to consumers.... The high percentage of contaminated plants [54\%] and their neonicotinoid concentrations suggest that this problem is widespread, and that many home gardens have likely become a source of exposure for bees.

This study shows the extent to which neonicotinoid pesticides can affect the surrounding environment beyond the traditional use of a massive spraying. It also serves as an important example of how common the use of neonics is, even when consumers are unaware of their presence. Marketing plants as 'bee friendly' just because they haven't been sprayed with neonicotinoids is something some cities want to prevent. More on the extent of the use of neonics will be discussed during Chapter 2, in the actual application of the risk assessment I develop in order to evaluate the use of these systemic pesticides.

Another city that has taken legislative steps to prevent the use of neonics is Spokane, Washington. Spokane placed a ban on the use of neonics in June 2014, following Eugene's lead. Spokane's ban stemmed from similar motivations as a reaction to the massive bee die-off that occurred in Wilsonville, OR in 2013. The ban is similar in nature to the Portland and Eugene bans in that it prohibits the use of neonics on public property, but does not extend to privately owned property. The restricted use of neonicotinoids accounts for approximately $30 \%$ of Spokane. ${ }^{37}$

${ }^{37}$ Geranios, Nicholas K. "Spokane Bans Chemical That May Kill Bees." The Seattle Times, July
4, 2014. http://www.seattletimes.com/seattle-news/spokane-bans-chemical-that-may-kill- 
Seattle followed Spokane only a few months later, enacting a moratorium in September 2014 in a unanimous vote. ${ }^{38}$ The moratorium, like those passed in the Oregon cities and Spokane, applies to all city property in Seattle. Seattle differs, however, because it is a moratorium rather than a ban, so it is temporary in nature. The moratorium is in place until more evidence is collected on the exact nature of the effects of neonics. Through their action, Seattle has also called for a national moratorium on the use of the pesticides, pleading that the White House Task Force, U.S. Environmental Protection Agency, and Congress place a similar moratorium on use of neonicotinoids. Along with encouraging federal action, the resolution asks retailers within Seattle to stop selling plants, seeds or any other products that contains neonicotinoids." ${ }^{39}$ While the discussion of alternative pest management programs is outside of the scope of this thesis, it remains important to consider the types of effects that these bans would have on a national level. More on this is discussed in Chapter 2, particularly in terms of Criterion 5.

Some municipalities outside the Pacific Northwest are making changes, too. Stillwater, Lake Elmo, Saint Louis Park, and Shorewood, Minnesota have

bees/.

${ }^{38}$ O'Brien, Councilmember. Seattle Council Connection. http://council.seattle.gov/2014/09/25/council-bans-neonicotinoid-pesticides-on-city-land$2 /$.

39 "Seattle Joins the Growing List of Cities to Ban Bee-Killing Pesticides." Organic Consumers, September 2014. https://www.organicconsumers.org/news/seattle-joins-growing-listcities-ban-bee-killing-pesticides. 
enacted some type of ban or moratorium. Further, the entire state of Minnesota is currently (starting in 2013) considering a statewide ban of the chemicals. If the statewide legislative action takes place, Minnesota would be the first state to take this action. In 2013, Minnesota passed a bill prohibiting plants grown with the use of 'detectable levels' of neonics to be labeled as 'bee-friendly'. The decision was in response to public concern, and the legislature hopes to encourage consumers to purchase garden and household plants with the pollinators in mind. ${ }^{40}$

Other municipalities that have taken legislative action against the public use of neonicotinoids are Ogunquit, Maine, Skagway, Alaska, Sacramento and Encinitas, California, and Boulder, Colorado.

Encinitas, California banned the use of neonicotinoid pesticides on all city property in September 2014 in response to public concern about the environment and massive loss to local beekeepers (as much as 42 percent of their colonies ${ }^{41}$ ), so the Department of Parks and Recreation banned their use. Encinitas takes the use of pesticides so seriously that they are even implementing a trial of a park in the city that is completely pesticide free, and if

\footnotetext{
40 "Minnesota Passes Bill to Label Garden Plants for Pollinators." Beyond Pesticides: Daily News Blog, May 21, 2014. http://beyondpesticides.org/dailynewsblog/2014/05/minnesotapasses-bill-to-label-garden-plants-for-pollinators/.

${ }^{41}$ Whitlock, Jared. "Encinitas to Test Pesticide-Free Park." Encinitas Advocate, June 15, 2015. http://www.encinitasadvocate.com/news/2015/jun/15/encinitas-pesticide-parks-bees/.
} 
successful, the program could be implemented citywide. ${ }^{42}$ Sacramento has a similar ban on the use of neonicotinoids on city property.

The ban of pesticides in the municipality of Skagway, Alaska is the first ban in the state. This ban seems to go the furthest, by banning the sale and use of pesticides containing neonicotinoids on both public and private land. Ordinance 14-15 was passed in September 2014, and has what seem to be the most stringent guidelines. ${ }^{43}$

Ogunquit, Maine is thus far the only state on the East Coast that has taken a stance on the use of neonicotinoids, passing the ban in November 2014. Maine has been a national pioneer in organic farming practices and apprehensive toward the overuse of pesticides for decades. ${ }^{44}$

The potential connection between the use of neonics and Colony Collapse Disorder has also garnered the attention of those making changes on a regional level. The U.S. Fish and Wildlife Service's National Wildlife Refuge System is in the process of eliminating the use of neonicotinoids. ${ }^{45}$ The U.S. Fish and Wildlife Service's National Wildlife Refuge System is the first federal

\footnotetext{
${ }^{42}$ Whitlock, Jared. "Encinitas to Test Pesticide-Free Park." Encinitas Advocate, June 15, 2015. http://www.encinitasadvocate.com/news/2015/jun/15/encinitas-pesticide-parks-bees/.

43 "Garden City of Alaska" Passes Comprehensive Pesticide Ordinance, Bans Bee-Toxic Pesticides." Beyond Pesticides: Daily News Blog, September 25, 2014. http://beyondpesticides.org/dailynewsblog/2014/09/garden-city-of-alaska-passescomprehensive-pesticide-ordinance-bans-bee-toxic-pesticides/.

${ }^{44}$ Wright, Virginia M. "Ogunquit Leads the Way." Down East: The Magazine of Maine, November 2014. http://downeast.com/ogunquit-leads-the-way/.

${ }^{45}$ Woody, Todd. "The U.S. Bans GMOs, Bee-Killing Pesticides in All Wildlife Refuges." TakePart, July 2014. http://www.takepart.com/article/2014/07/31/us-bans-gmos-bee-killingpesticides-national-wildlife-refuges.
} 
entity to take this stand on the use of neonics. The plan calls for a complete disposal of the use of all neonicotinoids and the use of genetically modified crops by January 2016 in the entire Pacific Region ${ }^{46}$. The U.S. Fish and Wildlife Service's National Wildlife Refuge System is responsible for 150 million acres of protected land throughout the country, specifically in Idaho, Oregon, and Washington-all of which will be protected from neonicotinoids.

Another federal initiative was initially proposed by Congressmen Earl Blumenauer in 2013, The Save America's Pollinators Act of 2013. This bill is a call for Oregon and the rest of the country to ban the use of neonics. The Save America's Pollinator's Act of 2013 aimed to accomplish the ban primarily through a demand that the Environmental Protection Agency (at least temporarily) no longer allow the use of neonicotinoids,

Saving America's Pollinators Act of 2013 - Requires the Administrator of the Environmental Protection Agency (EPA) to suspend the registration of imidacloprid, clothianidin, thiamethoxam, dinotafuran, and any other members of the nitro group of neonicotinoid insecticides to the extent such insecticide is registered under the Federal Insecticide, Fungicide, and Rodenticide Act (FIFRA) for use in seed treatment, soil application, or foliar treatment on bee attractive plants, trees, and cereals until the Administrator has made a determination that such insecticide will not cause unreasonable adverse effects on pollinators.

\footnotetext{
${ }^{46}$ Sarich, Christina. "Win! U.S. Fish \& Wildlife Service to Ban Use of Bee, Bird and ButterflyKilling Neonicotinoids." Nation of Change, July 29, 2014. http://www.nationofchange.org/win-us-fish-wildlife-service-ban-use-bee-bird-and-butterflykilling-neonicotinoids-1406642902.
} 
Blumenauer's motivation and Congress' support for this legislation rests on several primary observations about the harmfulness of neonics. Please see the appendix for an excerpt of the official bill, HR 1284, that highlights many of the reasons and concerns. ${ }^{47}$

This bill showcases the level of attention that the connection between neonics and their potential effects on pollinator population have been garnering - up to the federal level. Not only does the legislation call for at least a temporary suspension of registration of neonics, but even when regular rules are put back in place there must exist regular monitoring to constantly check the levels, effects, and uses of these types of pesticides. This is potentially an important addition to the bill because often times pesticides are approved for registration once and then not checked again for decades.

Policy development like these bans and bills surrounding the use of neonicotinoids are important in and of themselves to ban the use of neonics. But they are important in another way, too. Focusing on the regulations leads to another question: why isn't there more collective action on this issue to develop market solutions? Why are strides to protect pollinators in a municipality or city by and large the result of legal regulation? The answer, I think, primarily comes from the fractionalization of the pollination industry. Most farmers and agricultural producers do not themselves provide bees or pest management for their crops. Instead, various commercial beekeeping companies truck millions

${ }^{47}$ See Appendix, HR 1284 
of bees around the country during different blooming and pollination seasons for different crops. So, in many ways, the farmer's aren't seeing the loss of the pollinators the way that beekeepers are. This disenfranchises many farmers from movements to protect pollinators.

Farmers are also rarely the ones applying pesticides themselves. Instead, licensed professionals are responsible for their application. Therefore, the farmer's are often unaware of the precautions involved, how toxic the chemicals can really be, and again are often disengaged from the process.

This fractionalization of the three main parties involved in agricultural production and the use of neonicotinoid pesticides plays a key role in collective action failures to prevent market solutions. 


\section{Pollinators in Court}

Neonicotinoid pesticides have also been at issue in recent federal regulation in the United States. The 9th Circuit Court of Appeals has overturned the EPA's approval of Sulfoxaflor, a type of neonicotinoid. The pesticide was approved in 2013 after an initial call for additional studies was rerouted to approval with minimal further restrictions added in application guidelines ${ }^{48}$. Initially, the pesticide was denied because of the potential detrimental effects on pollinators.

These policy regulations on neonic pesticides beg the question: are they justified? Moreover, for every city that has adopted some type of policy regulation on the use of neonics, there are hundreds that have not. The divide on whether to implement such policies rests in the question of evidence. This lack of certainty leads to a main question in this thesis: what sort of guidelines are there for policymaking in the face of evidentiary uncertainty?

\footnotetext{
48 "Petitioners v. U.S. Environmental Protection Agency." United States Court of Appeals for the Ninth Circuit: Case 13-72346, September 2015 http://earthjustice.org/sites/default/files/files/sulfoxaflor-opinion.pdf.
} 


\section{Thesis Question/Argument}

The potential harm caused to bees and other pollinators by the rampant use of neonicotinoids has the capacity to pose a real and immediate threat to both the environment and humans. The benefits that bees and other pollinators provide, combined with the potential of harm they may face, are important enough to warrant a more comprehensive testing apparatus by which to evaluate threats to their population. Environmentally, bees and other pollinators are an important piece of ecosystemic balance - from pest management to pollination of plants that are a part of many species' diet. Anthropologically speaking, the way of life humans have been accustomed to and even need in order to survive is also largely dependent on a healthy population of bees and other pollinators; up to $70 \%$ of plants and vegetables we eat are directly a result of pollinators, and one third of every mouthful humans consume is attributed to pollinators' arduous work. Without a healthy population of pollinators, the agricultural variety and nutritional availability would drastically decrease. Moreover, these agricultural products pollinators are responsible for also affect billions of dollars on both a national and global level. ${ }^{49}$ In many ways, the economic stability of the United States is at an equal risk as the pollinators. For example, an inability to produce many of our own agricultural staples would leave local and regional livelihoods disrupted and change the United States' import/export position. Moreover, this

\footnotetext{
${ }^{49}$ Trumble, John T. "The Dependence of Crops for Pollinators and the Economic Value of Pollination in Brazil." Journal of Economic Entomology, May 4, 2015.
} 
is not just a national problem. Pollinators are responsible for over 150 billion dollars globally in agriculture. ${ }^{50}$ Many of the nutrients humans need to be healthy would be in short supply.

The vast array of benefits that bees and other pollinators provide humans and the environment make them a critical aspect of our ecosystem and it's balance. The potential threat that neonics pose to the well being of pollinators, health of their population, and this ecosystemic balance all warrant a closer look at the effects of neonics on their existence. While scientists continue to study the possible effects of neonicotinoids on pollinators, how should policy makers respond? In this thesis, I argue that the various and drastic ways in which pollinators impact our environment and every day life, combined with the potential of the harsh threats their collapse would entail, warrant a more stringent approach to the evaluation of potential harms like neonicotinoids. An ethical risk assessment, as I define one, would be an appropriate tool to apply to this situation to guide policy makers in drafting regulations even in the absence of scientific certainty. Ethical risk assessments are a tool by which to evaluate the moral and ethical responsibilities in a whole host of different scenarios, one of which is neonics and pollinators. In other words, this ethical risk assessment will be used as an instrument by which to determine whether or not there is a sufficient risk to the population of

\footnotetext{
${ }^{50}$ Gallai, Nicola, Jean-Michel Salles, Josef Settele, and Bernard E. Vaissiere. "Economic Valuation of the Vulnerability of World Agriculture Confronted with Pollinator Decline." Ecological Economics 68, no. 3 (January 15, 2009): 810-21.
} 
pollinators, thus determining whether regulation is appropriate. Through application of this risk assessment, I will show that in this particular case regulation is appropriate due to the risks neonics pose to pollinators in light of the evidence that we do have.

In the next chapter, I develop a set of criteria for an ethical risk assessment. The criteria are a result of a combination of existing literature and some novel connections I draw here. This list, I argue, is what constitutes an ethical risk assessment. Ethical risk assessment, grounded in Utility Theory, is appropriate here because of its calculative apparatus and sociopolitical applicability.

The question that prompted this thesis essentially asks whether the local legislation in cities like Portland and Seattle that has been passed to protect pollinators from neonicotinoids is justified. Moreover, should legislation be passed nationally? By justified, I mean the appropriate and morally defensible action (legislative ban) to solve an identified problem (declining population of pollinators). I argue that when my ethical risk assessment is applied, it is shown that the effects of neonics on bees and other pollinators is real and substantial enough to warrant regulation like legislative action (bans), thereby making the legislative bans justified.

I introduce Utility Theory as the appropriate theoretical framework to act as the foundation for the criteria I develop that make up an ethical risk assessment. Utility Theory is particularly appropriate here, I think, because 
inherent in Utilitarianism is a calculation of values in a given scenario. Moreover, Utility Theory is fitting here in part because it compares the values of a given scenario in a larger picture that concerns social and political elements (rather than only individual results). I will show how using Utility Theory leads quite fluidly to the use of an ethical risk assessment. Then I will discuss the criteria I have developed that constitute an ethical risk assessment. Next, I will apply these criteria to the effect of neonics on pollinators in order to conduct this ethical risk assessment. This will include reasons why bees and other pollinators ought to be protected, and explain how my ethical risk assessment portrays the EPA's current standards as insufficient for providing a comprehensive or accurate reflection of the impact of neonics on pollinators. I develop these criteria based on existing literature in combination with those I find important based on my own research. Finally, I will conclude that through the application of an ethical risk assessment to these circumstances, regulation is justified given the scientific uncertainty and the high level of risk that humans and the environment face if the pollinator population continues to decline at this rate. 


\section{CHAPTER ONE: Utilitarianism and an Ethical Risk Assessment}

The previous section discussed the benefits, as well as the potential harms, of the use of neonicotinoid pesticides. Some evidence currently available suggests neonics may be harmful. However, existing evidence is not enough to outright determine whether their use should be regulated. It is enough, however, to warrant the question: how do we as citizens and policymakers evaluate whether action (regulation) is justified? In this thesis, I argue that in situations where evidence is not immediately conclusive, an ethical risk assessment ought to be applied as a tool by which we can incorporate and evaluate ethical dilemmas like the use of neonicotinoid pesticides in order to determine whether regulation is justified.

An example of how an ethical risk assessment might be used in a different context would be the fluoridation of public drinking water. In this scenario, too, there has been debate over the risk posed by an action (whether the fluoridation of public drinking water poses a significant risk). ${ }^{51}$

To perform an ethical risk assessment, the benefits and potential harms are weighed against each other. Then, a decision is made in favor of the factors that more intensively and generally have greater effects. The fluoridation of public drinking water is a good example of the application of an ethical risk assessment because, first and foremost, it is inherently an ethical concern: we

\footnotetext{
51 "Water Fluoridation and Cancer Risk." Accessed November 30, 2015. http://www.cancer.org/cancer/cancercauses/othercarcinogens/athome/water-fluoridationand-cancer-risk.
} 
have an ethical obligation to protect public health. Water fluoridation is more clear-cut than the issue of neonics and their impact on humans and the environment. The potential effects of fluoride in water is much more direct, traceable, and there is simply more data available. There is also relatively more conclusive evidence that fluoridation of public drinking water is not harmful ${ }^{52}$ than there is on the (potential) harm of neonics. The benefits of fluoride in water are in the interest of public health, showing significant reduction in dental cavities. ${ }^{53}$ In the issue of public drinking water fluoridation, it is clear that the benefits drastically outweigh the risks. Therefore, it could be argued that waterfluoridation ought to be required, or at least that doing so can be ethically justified.

The application of an ethical risk assessment will not always produce the conclusion that regulation is justified. The example of the fluoridation of public drinking water was used primarily to give the reader a quick overview of how an ethical risk assessment might be applied as a tool to guide policymakers in situations where it is not immediately clear what type of risk is posed, and in these situations how it might be determined as to whether or not regulation is justified (and should thus be enforced).

\footnotetext{
${ }^{52}$ Newbrun, Ernest. "The Safety of Water Fluoridation." The Journal of the American Dental Association 94, no. 2 (February 1977): 301-04.

${ }^{53}$ Evans, RW, ACY Hsiau, PJ Dennison, A. Patterson, and B. Jalaludin. "Water Fluoridation in the Blue Mountains Reduces Risk of Tooth Decay." Australian Dental Journal 54, no. 4 (December 2009): 368-73.
} 
Risk assessments can be integral to evaluating and developing policy that affects environmental and public health. Mark G. Robson and William A. Toscano discuss that 'risk' can pertain to either loss or reward. ${ }^{54}$ Here, 'risk' refers to the potential loss of environmental stability via the potential negatively impacted health of pollinators. These potential negative impacts on pollinators would inevitably place negative strains on other life forms as well, including humans - from economic stability and agricultural variation, to ecosystemic longevity. The potential risks to these facets of health and well-being are in part what make an ethical risk assessment necessary here: there is an ethical obligation to create policy that protects these elements.

The protection of human health and the environment, a common phrase found in many federal statutes, is based on a fundamental tenet: that of not harming human health and therefor not increasing risk to health. ${ }^{55}$

Because of the high stakes involved in the decline of pollinators, it is of the utmost importance to apply an ethical risk assessment to potential threats to their health. Robson and Toscano establish that an attempt for zero risk is not feasible due to the amount of variables in a given scenario. However, zero risk is not the goal of this thesis, either. Instead, the goal here is to find a way to evaluate whether a legislative ban on neonicotinoid pesticides can be ethically

\footnotetext{
${ }^{54}$ Robson, Mark G., and William A. Toscano. Risk Assessment for Environmental Health. Vol. 2. Public Health/Environmental Health. John Wiley \& Sons, 2007.

${ }^{55}$ Robson, Mark G., and William A. Toscano. Risk Assessment for Environmental Health. Vol. 2. Public Health/Environmental Health. John Wiley \& Sons, 2007. P 5.
} 
justified, even when uncertainty remains. In order to determine whether regulation is justified, I will apply an ethical risk assessment. Here, an ethical risk assessment acts as a neutral or objective means of evaluation through its comparison of potential gains and losses on an environmental, agricultural, health, and nutritional aspects while maintaining an ethical standpoint. 


\section{Historical and Normative Principles of Utility Theory}

In the previous section I concluded that an ethical framework is the best approach to determining whether the regulation of neonic pesticides is justified. This is particularly the case because of the needed comparison between the benefits and risks to the use of neonics; inevitably, a gain for one position can be a loss for the other. Here, I will establish that Utilitarianism is the appropriate ethical framework by which to navigate between these benefits and potential risks.

I argue that Utility Theory is the suitable ethical framework for three main reasons: first, a foundation of Utilitarianism is its ethical component; Utilitarianism provides justification for the use of an ethical risk assessment by capturing the moral obligation to protect the health and well-being of humans and the environment. Secondly, inherent in Utilitarianism is it's calculative method by which to compare gains/losses and benefits/risks -something that is foundational for the ethical risk assessment I will perform in the next chapter. And third, because of the intrinsic sociopolitical layer of Utilitarianism. These reasons will be discussed in more detail following the historical context of Utilitarianism. Utilitarianism is also a preferable foundation to policy development because it takes into account values beyond those that are anthropocentric. Instead, Utilitarianism places value not only on humans, but on the environment and its inhabitants for their own sake. 
First, I will provide a historical context for Utilitarianism in order to demonstrate why this framework so fluidly leads into the use of the five criteria I have created that together form an ethical risk assessment, and also to demonstrate why an ethical risk assessment is preferable to a traditional risk assessment. Following the historical context discussion, I will outline my five criteria for an ethical risk assessment, which includes a discussion of each individual criterion in more detail.

Jeremy Bentham is often referred to as the 'Father of Utilitarianism.' Bentham introduced a new way of understanding human behavior: in a calculative schema. Bentham essentially argued that human behavior isn't governed by society or natural rights; humans are governed by a calculation of pleasure and pain. Bentham's goal then became to establish a mathematical equation by which to understand every human act.

Humans, Bentham argues, naturally seek pleasure and reduction of suffering. Thus, humans act in ways that will increase their pleasure and reduce their pain; or, for the purpose of this thesis, increase their 'gains' (utility) and decrease 'loss'. Bentham posits this is what primarily drives human action,

Nature has placed mankind under the governance of two sovereign masters, pain and pleasure. It is for them alone to point out what we ought to do, as well as to determine what we shall do. On the one hand the standard of right and wrong, on the other the chain of causes and effects, are fastened to their 
throne. They govern us in all we do, in all we say, in all we think... ${ }^{56}$

Bentham then constructed his Hedonistic Calculus, which he asserted determined the actions of peopled. This is how people calculate a given scenario's gain (utility) or loss, Bentham said. The calculation also takes into account aspects like intensity, extent, and duration of the anticipated pleasure/pain or gain/loss, thus driving a particular behavior.

Bentham established another central component to Utilitarianism: the Greatest Happiness Principle. This is the principle that is most critical for the purpose of this thesis, particularly because the drastic reduction of the population of bees and other pollinators has significant negative impacts sociopolitical, communal elements like human health, the environment, and the economy. The Greatest Happiness Principle also establishes that humans should act in ways that promote the greatest aggregate of happiness. The role of government then, according to Bentham, is to act to promote the greatest good for the greatest amount of people.

The Principle of Utility is the foundation of the present work: it will be proper therefore at the outset to give an explicit and determinate account of what is meant by it. By the Principle of Utility is meant that principle which approves or disapproves of every action whatsoever, according to the tendency it appears to have to augment or diminish the happiness of the party whose interest is in question: or, what is the same thing in other words, to

\footnotetext{
${ }^{56}$ Bentham, Jeremy. An Introduction to the Principles of Morals and Legislation. Oxford: Clarendon Press. 1907. Library of Economics and Liberty [Online] available from http://www.econlib.org/library/Bentham/bnthPML1.html
} 
promote or oppose that happiness. I say of every action whatsoever, and therefore not only of every action of a private individual, but of every measure of government. ${ }^{57}$

Some of Bentham's contemporaries, such as the romantics, interpreted Bentham's calculative approach as the reduction of humans into calculating mechanistic machines that only act in accordance with the calculations they have made surrounding their own self interest. Bentham responded that it is not enough to ask people whether they 'agree' or 'disagree' or vote 'yes or no'. For Bentham, society is the sum of its parts; collective interest is nothing more than the sum of its interests. Bentham maintains that while his account may be calculative in nature, it is realistic to operate under the assumption that people want to experience pleasure and avoid pain/suffering. Moreover, the aggregate application of Utilitarianism is very much what it means to be a society, with roots in the notion of a Social Contract Theory (SCT); society is made up of its parts. To experience the benefits of societal membership, then, citizens ought to participate. This individual calculation, combined with the aggregate concern, is in part what makes Utilitarianism such an appealing framework by which to approach an ethical policy matter like the use of neonics.

John Stuart Mill builds on Bentham's version of Utilitarianism. For Mill, too, the aggregate affect is a key feature of Utilitarianism. To strive for the greatest amount of good for the greatest amount of people inherently

\footnotetext{
${ }^{57}$ Bentham, Jeremy. An Introduction to the Principles of Morals and Legislation. Oxford: Clarendon Press. 1907. Library of Economics and Liberty [Online] available from http://www.econlib.org/library/Bentham/bnthPML1.html
} 
contributes a societal element. Mill describes the basis of Utilitarianism as, "actions are right in proportion as they tend to promote happiness, wrong as they tend to produce the reverse of happiness." 58

Another criticism that Utilitarianism is charged with is that the framework focuses too much on the aggregate effect, which in effect ignores individual rights. This can be seen most prominently in situations where minorities become further disenfranchised from the greater society. This is a risk in my model for issues such as world hunger. To a certain extent, this issue is a shortcoming of Utilitiarianism, and thus my model's ability to completely address issues in pockets of disenfranchised populations.

However, John Stuart Mill replies to this criticism by establishing that Utilitarianism is actually a structure that preserves individual rights within a governmental structure. This is because a citizen's interest in avoiding pain and seeking pleasure, says Mill, leads citizens to pursue policy and law that mirrors these interests, which encourages citizens to become engaged in government, thereby building a representative democracy. Mill establishes that a representative democracy includes elements of rationality and virtue into an otherwise purely operative governmental structure. Thus, for Mill, a representative democracy is the preferable structure of government.

The Utilitarianism calculative method where the goal is the greatest happiness for the greatest amount of good is, I think, preferable for several

\footnotetext{
${ }^{58}$ Mill, John Stuart. Utilitarianism. Longmans, Green, Reader, and Dyer, 1871.
} 
reasons. First, this model most closely resembles a democracy. While not each person's queries may not be able to be addressed, catering to the most people in a society is the greatest asset of and weakness shared by both a democratic structure and a Utilitarian approach to ethics.

I chose to select a theory that is based more on what is good and enforceable than what is right (like, for example, a Rawlsian approach that focuses on the good of all citizens). This decision was one that primarily concerned the applicability to a governing structure; I chose Utilitiarianism because of it's ability to synchronize with the democratic structure we aim to guide policymaking in the United States today.

Another criticism faced by Utilitarianism is that critics say it can be very difficult, or even impossible to compare the value result of a Utilitarianism calculation for a given situation. However, a Utilitarian could respond by arguing that this is essentially these types of ethical concerns that Utilitarianism can be so helpful. In fact, Bentham included elements like duration and intensity to construct a more elaborate mechanism by which to compare values. Elements like this will be incorporated into my ethical risk assessment so that a thorough comparison of values is attainable. 


\section{Utilitarianism as it leads to an Ethical Risk Assessment}

Utilitarianism provides a useful framework that includes ethical, calculative/comparative, and sociopolitical components by which to evaluate policy where evidence remains uncertain. First, Utilitarianism provides a workable framework for how to apply the knowledge gained through an ethical risk assessment in an ethical way (e.g., that we have a moral obligation to protect human and environmental health). Utilitarianism ultimately claims that moral obligation lies in the concept of communal beneficence: one ought to do what constitutes 'the greatest amount of good for the greatest amount of people. ${ }^{.59}$ The basic notion of Utilitarianism concerns the greatest amount of happiness for the greatest number. The normative argument is that the principle of utility ought to be the basis for our individual, as well as political, morality. Those who prescribe to Utilitarianism, such as Jeremy Bentham, John Stuart Mill, and Peter Singer, believe that the goal of society is to increase general welfare and decrease suffering. There is a moral obligation to first develop a way in which potential threats (like neonicotinoids) ought to be evaluated, and to act in accordance with the findings of the ethical risk assessment.

Second, inherent in Utilitarianism is a calculative method by which to compare potential gains/losses and pleasures/pains, or a result in "utility" after

\footnotetext{
${ }^{59}$ Mill, John Stuart. Utilitarianism. Longmans, Green, Reader, and Dyer, 1871.
} 
these factors have been compared. Moreover, as noted by William Cooper, the relationship between humans and the environment is complimentary. ${ }^{60}$ Nicholas P. Guehlstorf emphasizes the importance of a workable ethical framework, adding that it can not only assess and establish policymaking, but take it farther, "... if governmental practices of risk clarify the liberal goals of its bureaucratic agencies, American public policy might be able to interpret correctly and react appropriately to the risks it actually encounters with respect to the environment." ${ }^{\prime 61}$ Manuel Velasquez et al. discuss the calculative nature of Utilitarianism ${ }^{62}$, and the importance of including the costs of the choices available, "To discover what we ought to do in any situation, we first identify the various courses of action that we could perform. Second, we determine all of the foreseeable benefits and harms that would result from each course of action for everyone affected by the action. And third, we choose the course of action that provides the greatest benefits after the costs have been taken into account." ${ }^{63}$ In its calculations, Utilitarianism considers human health, pollinator health, and environmental health, rather than just providing consideration for exclusively one of these entities in the equation. This is the case not only

\footnotetext{
${ }^{60}$ Cothern, C. Richard. Handbook for Environmental Risk Decision Making: Values, Perceptions, and Ethics. CRC Press LLC, 1996.

${ }^{61}$ Guehlstorf, Nicholas P. "The Utilitarian Assessment." The International Library of Environmental, Agricultural and Food Ethics The Political Theories of Risk Analysis, 2004, 45-75.

62 "Velasquez, Manuel, Claire Andre, Thomas Shanks, and Michael J. Myer. "Calculating Consequences: The Utilitarian Approach to Ethics." Calculating Consequences:The Utilitarian Approach to Ethics 2, no. 1 (1989).

${ }^{63}$ Velasquez, Manuel, Claire Andre, Thomas Shanks, and Michael J. Myer. "Calculating Consequences: The Utilitarian Approach to Ethics." Calculating Consequences:The Utilitarian Approach to Ethics 2, no. 1 (1989).
} 
because the benefits would be spread beyond humans, but because human health is directly and indirectly impacted by the state of pollinators and the environment. Calculation of the highest utility is essential when performing an ethical risk assessment because it allows the assessment to accurately quantify gains and losses to different parties (which all impact one another), which then acts as a measurement of risk and utility.

Third, Utility Theory is also able to embody political or societal elements that are necessary for consideration in an ethical risk assessment, particularly as it pertains to the environment. Generally in environmental risk assessment and/or environmental politics, political science is absent. This is the case despite the astronomical increase in interest in environmental health and politics from government agencies, NGO's, non-profits, and the general public. Susan Baker, Katarina Eckerberg and Anna Zachrisson ${ }^{64}$, the increased attention and drive to engage in ecological restoration will affect the public, politics, and policy at an equally unprecedented rate, "In the contemporary period, restoration is being used in more diverse ways and for the purpose of higher-scale policy objectives...As a result, an intensification of both government and corporate engagement in restoration initiatives can be expected." ${ }^{65}$ Baker et. al, posit that these movements are leaving a sort of gap in the chain of analysis and implementation. These inevitable conflicts between

\footnotetext{
${ }^{64}$ Baker, Susan, Katarina Eckerberg, and Anna Zachrisson. Political Science and Ecological Restoration 23, no. 3 (October 11, 2013): 509-24.

${ }^{65}$ Baker, Susan, Katarina Eckerberg, and Anna Zachrisson. Political Science and Ecological Restoration 23, no. 3 (October 11, 2013): 509-511.
} 
analysis, implementation, and public policy require political science to play a strong role in an ethical environmental risk assessment and conservation initiative. $^{66}$

Nicholas P. Guehstorf similarly notices the gap of political theory involved in environmental issues, particularly as it pertains to environmental risk policy. According to Guehstorf, environmental risk policy is largely barren of any political theory analysis,

No study of environmental Risk Policy includes any sustained examination of how political theory applies or ought to apply in the process. This omission is noteworthy because the political theory can be a topic for understanding the evaluations made in natural resource policymaking as well as a methodology for discerning the decision-making processes in an environmental political administration. ${ }^{67}$

Utilitarianism, I argue, is the appropriate way to fill this gap that currently exists in environmental policy. Utilitarianism includes the utility of pollinators, which is directly linked to the utility of humans (through agricultural variation and the nutrition this provides, through economic sustainability and ecosystemic longevity). Utilitarianism's focus on the aggregate necessarily these sociopolitical, socioeconomic, and public health concerns into the system itself, so that these factors are an inherent aspect of the ultimate calculation of utility

\footnotetext{
${ }^{66}$ Baker, Susan, Katarina Eckerberg, and Anna Zachrisson. Political Science and Ecological Restoration 23, no. 3 (October 11, 2013): 509-24.

${ }^{67}$ Guehlstorf, Nicholas P. "The Utilitarian Assessment." The International Library of Environmental, Agricultural and Food Ethics The Political Theories of Risk Analysis, 2004, 45-75.
} 
that Utilitarianism provides. That is, because of the focus on the aggregate, Utilitarianism is able to provide a calculation that is best for the overall society, rather than a particular species, individual, or group of individuals. 


\section{Criteria}

In this section, I will discuss the five elements I have identified as necessary to perform an ethical risk assessment. Here, I will establish how the prescription to Utilitarianism logically leads to the use of these five criteria. In the next chapter, I will apply each of the five criteria to perform an ethical risk assessment of the use of neonicotinoid pesticides and their impact on pollinators, and thus humans.

The first four criteria are adopted from Robson and Toscano. The authors assert that these elements are integral to performing an ethical risk assessment, and I very much agree: (1) Hazard or Stress Identification, (2) Dose-Response Assessment or Analysis of Effects, (3) Exposure Assessment, and (4) Risk Characterization.

I chose to integrate these four criteria established by Robson and Toscano for several reasons. These four criteria are of particular importance because each criterion (both on its own and in combination with the other criteria) provides a more comprehensive picture of the value being assessed for risk, or potential hazard. These criteria are essential in ascertaining the risk of a particular identified potential hazard (here, the use of neonics) because they (1) consider the harmful elements, (2) measure the extent and significance (such as toxicity) of the hazard, (3) measure the duration and/or frequency of exposure to the hazard, and (4) measure the risk assessment of the projected 
impact of the hazard on the environment, humans, pollinators, plants, etc. ${ }^{68}$ and how these effects can in turn impact other sociopolitical structures like economic sustainability and agricultural variation. These criteria are particularly applicable in this thesis because they specifically consider impacts on the environment, and the different exposure levels, concentrations, and extent of the use of a potential hazard. According to Robson and Toscano, a combination of these methods is often used when attempting to determine the risk to public or environmental health. I will argue that all four of these criteria ought to be included in the overall criteria for environmental risk assessment I will develop in this chapter, as each criterion retains a different element that is equally as important for determining the potential risk of the use of neonics.

There is an additional criterion I have developed that I argue ought to be included in the operating list of criteria which must be met in order to perform an ethical risk assessment on an identified potential hazard or risk (which is, in this case, the use of neonicotinoids). The addition of criterion (5) is what essentially constitutes this risk assessment as ethical. I developed this criteria based on my reading of William Cooper's book "Values and Value Judgments in Ecological Health Assessments," where he emphasizes the importance of an evaluation of risk that contains a comparison of the values gained and lost on behalf of each party. This seems of particular importance to me, especially to

\footnotetext{
${ }^{68}$ Robson, Mark G., and William A. Toscano. Risk Assessment for Environmental Health. Vol. 2. Public Health/Environmental Health. John Wiley \& Sons, 2007.
} 
maintain an objective evaluation in this ethical risk assessment; comparing the value of the gains/losses of each party assures that each party is being represented. Moreover, what is a gain for one may be a loss for another, so the extent of the values/losses for each must be decided upon with regard to comparison of the other parties. Criterion (5) consists of understood comparative values of hazard and properties harmed by the hazard i.e., what is the value of the use of the hazard (neonics) compared to the value of prohibiting its use? Criteria (5) is particularly important because it communicates the importance of preservation of the environment not only for the good of the environment or pollinators in and of themselves, but because human health is directly and indirectly linked to the health of the environment and pollinators.

In his work, "Values and Value Judgments in Ecological Health Assessments," William Cooper discusses the importance of understanding this cyclical well being, "There is a value judgment in comparing ecological and human health - which is more important? This relationship is not competitive, it is complimentary. In real life you do not have a choice-if you want to maintain a high level of human health you must invest in the environment." (p. 4) ${ }^{69}$. Thus, the comparative element in criteria (5) compares the value of the use of systemic pesticides (say, for example, less pest infestations, higher crop yield,

\footnotetext{
${ }^{69}$ Cooper, William. "Values and Value Judgments in Ecological Health Assessments." Values, Perceptions, and Ethics Handbook for Environmental Risk Decision Making, 1995.
} 
etc.) to the prohibition of systemic pesticides (for example, less bee deaths). Accordingly, I argue that criteria (5) ought to be added to the four original criteria put forth by Robson and Toscano.

The addition of Criterion (5) into the ethical risk assessment framework is necessary to compare the values of the affected parties (humans, the environment, and pollinators) in order to determine the overall net gains and losses for each affected party. The inclusion of Criterion (5) moves the performance of the risk assessment beyond simply an assessment of the effects, to a more comprehensive value comparison. This assures an evaluation that is objective and takes all affected parties' net gains and losses into consideration. Moreover, the addition of criterion (5) is what turns a traditional risk assessment into an ethical one; ethical considerations now extend from solely the human realm into the realm of the environment. The advantage of the extent of ethical considerations to the environment is twofold: first, the environment (including bees and other pollinators, plants, etc. is beneficial in and of itself. Second, extending ethical consideration to the environment is good for humans; the environmental effects discussed in this thesis have direct and real consequences on human comfort and health, such as agricultural variation and economic stability. These net gains and losses are then comparatively analyzed, which determines the best outcome overall, for both humans and the environment. Utility Theory provides an adequate model to calculate these net losses and gains, and compare them on a sociopolitical 
level. The ability of Utility Theory to provide not only a net calculation of gains and losses, but to apply them on a sociopolitical level is what makes Utility Theory the most attractive framework. Indeed, Utility Theory is inherently an ethical framework, and is able to compare the values of the affected parties on a level that is applicable on both a local and global plane. The comparative values that are necessary to be evaluated are those of (1) the use of neonicotinoids in terms of crop yield and convenience, and (2) environmental health, human health, and the stability of the socioeconomic elements like economic stability and agricultural variation. These values will be compared because each represents the agents that are primarily affected by the use of neonicotinoids. Determining the net gains/losses for each affected group is essential to determine a net calculation of overall gains and losses. Whichever group displays the most losses (and, theoretically, highest gains) in this context will represent the party who's effects shall be primarily considered during policy formation and development.

Utility Theory provides more than an ethical comparison of values. Utility Theory provides a framework by which to provide these calculations, since Utility Theory essentially consists of an apparatus by which to calculate utility, or the net gains and losses in a given scenario. Here, that utility will be the value of environmental and human health. I argue that Criterion (5) is essential to performing an ethical risk assessment, and further that Utility Theory 
encompasses this complimentary value system of criteria (5), environmental and human health.

Cooper discusses the difficulty in assigning exact probabilities of events when developing these values. This will be an issue in this thesis as well, as it is both difficult and beyond the scope of this thesis to determine or trace the exact impact of neonicotinoids. The incomplete picture of the exact effects of neonics is a large motivation for conducting an ethical risk assessment. As discussed earlier, the goal here is to use an ethical risk assessment as a tool by which to evaluate policy development in the absence of conclusive evidence of harm/utility.

However, even in the face of evidentiary uncertainty, those performing an ethical risk assessment must collect as much data as possible in order to ascertain the duration, extent, etc. of potential harm identified. Criteria 1-4 are essential to providing an ethical risk assessment because they take into account the potential damage of neonicotinoids. Criteria 1-4 provide a simple evaluation of the potential danger of the widespread use of neonicotinoids. Criteria 1-4 also provide an ethical element because these criteria test for further harm, such as toxicity level and the extent to which the chemicals seep into the environment, along with the duration of the side effects. Moreover, the criteria developed here test with an objective, neutral goal: to provide an accurate account of the effects of the use of neonicotinoids. The EPA standards currently used are tested for immediate, lethal affects that directly carry over to 
humans. This testing procedure doesn't carefully follow effects from the source, and only highlights one particular potential connection. Criteria 1-4, by contrast, test for the health and integrity of the environment in and of itself, as a whole entity. The additional testing that examine the effects on the environment for its own sake are more beneficial because it treats the environment ethically, as an entity rather than a stepping stone toward human convenience. Moreover, criteria 1-4 take into account more subtle and indirectly significant effects of neonicotinoids, which goes beyond the EPA's testing apparatus which only tests for immediate lethal effects to bees and other pollinators. Criteria (5) creates an ethical sphere within which these aspects identified in criteria 1-4 can be considered. The use of these 5 criteria to perform an ethical risk assessment provides a more in-depth analysis of potential risk of neonicotinoids than the EPA's testing mechanisms. Moreover, these criteria consider utility in making these kinds of policy decisions, where the EPA's current measures do not.

This list of the five criteria constitutes an ethical risk assessment sufficient to evaluate the use of neonicotinoids through a comprehensive and value comparative model, which will ultimately provide an ethical, objective review of neonicotinoid use as it affects the environment and pollinators, humans, and the socioeconomic elements discussed in this thesis. Additionally, I argue that Utility Theory is necessary for the realization of criteria (5). The inclusion of criterion (5) is what transforms this evaluation from one of a 
traditional evaluation to an ethical one. A detailed explanation of each criterion's vital role in performing an ethical risk assessment is discussed next. 


\section{CHAPTER TWO: Performing an Ethical Risk Assessment}

The potential negative effects of neonicotinoids have gained mostly local attention (as discussed in Chapter 1). Nationally, however, the Environmental Protection Agency (EPA) has taken some strides in testing for adverse effects of substances including neonicotinoids. Performance of these tests is primarily motivated by human health concerns/protection and environmental concerns/protection. In 2006 the Environmental Protection Agency adopted a review process that requires most pesticides currently in use to be evaluated every 15 years. That cycle schedules the next major review of pesticides to be in 2021. I argue that while the EPA's three-tiered system is progress from even only a decade ago, the current EPA's standards do not ask the correct questions in order to accurately determine where a ban of neonic pesticides is appropriate. The EPA's current model should instead be replaced with an ethical risk assessment. An ethical risk assessment is an apparatus more tailored toward answering complex questions regarding public and environmental health. Some of these complexities include developing a course of action in the face of evidentiary uncertainty, and more than one interested party when calculating net 'losses' and 'gains'. 


\section{Why the EPA's Guidelines Fall Short}

In 2011, the EPA responded to mounting concern regarding the effect of neonicotinoid pesticides by revamping their method by which to evaluate the harmfulness of pesticides on pollinators. Historically, the EPA performed risk assessments through qualitative studies. The newly developed framework consists of three main tiers of evaluation, with higher tiers incorporating more stringent evaluation. The system takes into account the varying application processes of the pesticides (for example, whether the pesticides are applied directly to the leaves or applied during the seed stage). Another central point of the EPA's evaluation of the safety of pesticides are the 'major routes of exposure' including exposure through diet or contact. ${ }^{70}$

Tier 1 acts as the initial screening phase, where pesticides are separated into two preliminary categories: pesticides that need further evaluation due to anticipated risk potential, and those that have presented minimal risk, and therefore require no additional risk analysis. Since Tier 1 is the initial assessment, it is generally performed conservatively, with an overestimation of the likelihood of exposure or potential for risk.

Those pesticides that have been categorized as having the potential for risk to public or environmental health (including pollinators) move on for further

\footnotetext{
70 "How We Assess Risks to Pollinators." EPA United States Environmental Protection Agency. United States Environmental Protection Agency, n.d. Web. 9 Aug. 2015.

<http://www.epa.gov/pollinator-protection/how-we-assess-risks-pollinators>.
} 
risk analysis at Tiers 2 and 3 . Tiers 2 and 3 are defined by the EPA as "more refined assessments" that include semi-field studies (Tier 2) and full-field studies (Tier 3). According to the EPA, Tier 2 studies may also include data from feeding studies and residue studies which examine pesticide effects on bees and their colonies through concentrations in pollen and nectar, and exposures to concentrations in a colony's food source. The EPA labels Tier 2 tests as best to be used, "Tier 2 studies can be used to characterize risk at the colony level. Because the information at this level, i.e., both exposure and effects information, is more specific to the actual use of the pesticide under review, it can also be used to identify risk mitigation options. ${ }^{.71}$ Next, the EPA establishes whether more information is needed, or if regulations should be shaped around the information provided from Tier 2 analysis. If Tier 2 does not yield conclusive enough results, the pesticide in question is moved on to a Tier 3 evaluation to obtain more information on potential risk. In Tier 3 evaluations, specific questions are addressed regarding the risks at the colony level and assess long-term effects on the colony. Additional and more detailed information regarding each Tier evaluation is provided in Table 1 below. ${ }^{72}$

\footnotetext{
71 "How We Assess Risks to Pollinators." EPA United States Environmental Protection Agency. United States Environmental Protection Agency, n.d. Web. 9 Aug. 2015. $<$ http://www.epa.gov/pollinator-protection/how-we-assess-risks-pollinators>.

72 "How We Assess Risks to Pollinators." EPA United States Environmental Protection Agency. United States Environmental Protection Agency, n.d. Web. 9 Aug. 2015. <http://www.epa.gov/pollinator-protection/how-we-assess-risks-pollinators>.
} 
Table 1: Data for Informing EPA's Pesticide Risk Assessment Process for Bees $^{73}$

\begin{tabular}{|c|c|c|}
\hline Test Title & Tier & Test Objective \\
\hline $\begin{array}{l}\text { Honey bee } \\
\text { adult acute } \\
\text { contact } \\
\text { toxicity }\end{array}$ & I & $\begin{array}{l}\text { Laboratory test that identifies the dose that is lethal } \\
\text { to half of the test population (LD50) by dermal } \\
\text { contact. }\end{array}$ \\
\hline $\begin{array}{l}\text { Honey bee } \\
\text { adult acute } \\
\text { oral toxicity }\end{array}$ & I & $\begin{array}{l}\text { Laboratory test that identifies the oral dose that is } \\
\text { lethal to half of the test population (LD50) by oral } \\
\text { ingestion. }\end{array}$ \\
\hline $\begin{array}{l}\text { Honey bee } \\
\text { larvae acute } \\
\text { oral toxicity }\end{array}$ & I & $\begin{array}{l}\text { Laboratory test that identifies the dose that is lethal } \\
\text { to half of the larval test population (LD50). }\end{array}$ \\
\hline $\begin{array}{l}\text { Honey bee } \\
\text { adult } \\
\text { chronic oral } \\
\text { toxicity }\end{array}$ & I & $\begin{array}{l}\text { Laboratory test that identifies effects following } \\
\text { repeat exposures (e.g., 10-day) to the test } \\
\text { compound. }\end{array}$ \\
\hline $\begin{array}{l}\text { Honey bee } \\
\text { larvae } \\
\text { chronic oral } \\
\text { toxicity }\end{array}$ & I & $\begin{array}{l}\text { Laboratory test that identifies effects on larvae } \\
\text { following repeat exposure to the test compound. }\end{array}$ \\
\hline $\begin{array}{l}\text { Honey bee } \\
\text { toxicity of } \\
\text { residues on } \\
\text { foliage }\end{array}$ & I & $\begin{array}{l}\text { Provides information on the amount of time during } \\
\text { which contact exposure to weathered residues of } \\
\text { the test compound remains toxic to }>25 \% \text { of the } \\
\text { adult bees. }\end{array}$ \\
\hline
\end{tabular}




\begin{tabular}{|l|l|l|}
\hline $\begin{array}{l}\text { Semi-field } \\
\text { testing for } \\
\text { pollinators }\end{array}$ & II & $\begin{array}{l}\text { Field-level test, where exposure to bee colonies is } \\
\text { conducted within enclosures; study provides } \\
\text { information on exposure as well as effects on a } \\
\text { whole colony. }\end{array}$ \\
\hline $\begin{array}{l}\text { Field } \\
\text { feeding } \\
\text { study }\end{array}$ & II & $\begin{array}{l}\text { Field-level test where bee colonies are located in an } \\
\text { open field setting, but exposure is delivered at } \\
\text { predetermined concentrations in either sucrose } \\
\text { solution or a pollen supplement. Field feeding } \\
\text { studies can provide information on long-term } \\
\text { effects. }\end{array}$ \\
\hline $\begin{array}{l}\text { Measure of } \\
\text { residues in } \\
\text { pollen and } \\
\text { nectar }\end{array}$ & II & $\begin{array}{l}\text { Provides exposure information (from the pollen and } \\
\text { nectar) following application of the product at label } \\
\text { rates. }\end{array}$ \\
\hline $\begin{array}{l}\text { Field testing } \\
\text { for } \\
\text { pollinators }\end{array}$ & III & $\begin{array}{l}\text { Field-level test that typically looks at long-term } \\
\text { effects under environmentally realistic exposure } \\
\text { conditions. }\end{array}$ \\
\hline
\end{tabular}

While this model may appear initially thorough, it is not without difficulties.

There are many avenues that this three-tiered framework is unable to evaluate, including direct connections or causes between pesticides and exposures. The EPA doesn't conduct their own independent tests. Instead, the manufacturer of the pesticide does the research and submits its findings to the EPA. For example, when David Mendes was researching the studies done that approve the registration of neonics, he was referred to a toxicologist at Bayer, which is the largest producer of pesticides in the United States. This issue presents another convincing reason why it is so important to provide an ethical risk 
assessment that serves as not only a more informed platform on which to make decisions, but an objective and unbiased one. This discussion highlights that the EPA standards are not only not stringent enough, but lack application that elicits practical and informative results. The windows within which testing is performed are too narrow. The Natural Resources Defense Council has also fervently spoken out against the EPA's approach to the registration of pesticides that have not been thoroughly evaluated. The passage of approximately $65 \%$ of pesticides on today's market have been done via the EPA's "loophole" of conditional registration, "NRDC spent several years examining federal government data and interviewing key officials, and has determined that the government has allowed the majority of pesticides onto the market without a public and transparent process and in some cases, without a full set of toxicity tests, using a loophole called a conditional registration. In fact, as many as 65 percent of more than 16,000 pesticides were first approved for the market using this loophole."74

When the EPA does perform its tests, the effects that are tested for only consider whether a bee essentially drops dead on contact. Tests need to instead include more stringent guidelines such as testing the effects at various intervals of time and for sub lethal effects as well. This need for more rigorous testing is starting to become a public and legal requirement: in 2015 The U.S.

\footnotetext{
${ }^{74}$ Sass, Jennifer, and Mae Wu. "Superficial Safeguards: Most Pesticides Are Approved by Flawed EPA Process." Natural Resources Defense Council: Issue Brief. National Resources Defense Council, n.d. Web. 9 July 2015. $<$ http://www.nrdc.org/health/pesticides/files/flawed-epa-approval-process-IB.pdf>.
} 
Court of Appeals for the Ninth Circuit agrees, explaining that, "Because the EPA's decision to unconditionally register Sulfoxaflor was based on flawed and limited data, we conclude that the unconditional approval was not supported by substantial evidence",75 (emphasis added). These are not evaluations performed in consistency with an ethical risk assessment. More care needs to be given to the testing standards, and what those standards look for. Systemic pesticides don't simply disappear after their application; many live in the soil, leaves, nectar, etc. of the plants for years to come. The current EPA standards fail to consider these issues and are not adequate to provide a comprehensive understanding of the risks neonicotinoids pose. In order to provide a more coherent picture of the effects of neonics on the environment, particularly pollinators like bees, an ethical risk assessment needs to be applied.

In addition, The White Paper in Support of the Proposed Risk Assessment Process for Bees, produced by the EPA and Pest Management Regulatory Agency Health Canada, was presented in 2012 to the Federal Insecticide, Fungacide, and Rodenticide Act (FIFRA) in support of the risk assessment of pesticides on pollinators. The White Paper essentially establishes that the current standards used by the EPA are not adequate to determine the true nature of the risk of the use of neonics. The White Paper identifies certain difficulties of the EPA's three-tiered system, "There are several

\footnotetext{
75 "Petitioners v. U.S. Environmental Protection Agency." United States Court of Appeals for the Ninth Circuit: Case 13-72346, September 2015 http://earthjustice.org/sites/default/files/files/sulfoxaflor-opinion.pdf.
} 
challenges that exist when integrating the various exposure and effects data that can be used to assess potential effects of pesticides on honey bees and their colonies. For instance, different bees are expected to be exposed to pesticides at different magnitudes, depending upon their function in the colony. In addition, interpreting the impacts of mortality and sub lethal effects on the ultimate survival of the colony is complicated by a lack of definitive understanding of the linkages between many of these endpoints. Colony-level simulation models represent a useful tool that may be used to integrate exposure and effects data with the complexities of the social structure and biology of a honeybee colony. ${ }^{\text {"76 }}$ The difficulty of evaluating a potential threat to human and pollinator health is a complicated endeavor, and the apparatus by which to perform this evaluation must be able to address these complications thoroughly. Indirect effects of neonicotinoid pesticides account for most of the damage done to pollinators like bees. In order to accurately gauge the level of threat these pesticides pose, a more elaborate evaluation structure ought to be used.

${ }^{76}$ USEPA. 2012. White Paper in Support of the Proposed Risk Assessment Process for Bees. Submitted to the FIFRA Scientific Advisory Panel for Review and Comment September $11-14,2012$. Office of Chemical Safety and Pollution Prevention Office of Pesticide Programs Environmental Fate and Effects Division, Environmental Protection Agency, Washington DC; Environmental Assessment Directorate, Pest Management Regulatory Agency, Health Canada, Ottawa, CN; California Department of Pesticide Regulation http://www.regulations.gov/\#!documentDetail;D=EPA-HQ-OPP-2012-0543-0004 
I argue that the application of an ethical risk assessment is the appropriate test to gauge the level of threat that neonicotinoid pesticides pose to pollinators like bees. The criteria I established in chapter one are the essential components of performing such an assessment. Below, I discuss each criterion in the context of an ethical risk assessment as applied to the evaluation of the impact of neonics on pollinators.

Criterion (1) Hazard or Stress Identification. First, the potential threat to the identified party must be ascertained. Here, I consider the impact of neonicotinoid pesticides (hazard or stress) on pollinators like bees (threatened party). Some questions that must be asked in order to apply this criteria might be: What types of pesticides pose a threat to pollinators? What elements of pesticides are most harmful to the pollinator population? It is of the utmost importance, I argue, to consider whether the pesticide is systemic. This is an important distinction because it establishes how the chemical might affect plants and pollinators. The primary distinction between systemic pesticides and traditional pesticides is that systemic pesticides stay within the plant structure 
and surrounding soil for years, at rates up to $50 \% .{ }^{77}$ Neonicotinoid pesticides are a type of systemic pesticide, and affect the plant and surrounding environment in this way. Effects of neonic pesticides on bees range from immediate to chronic. In many cases, the effect is not immediately lethal but instead affect pollinators' navigational, immune, and digestive systems over a span of several days or weeks, leaving the bees unable to return to their hive. Furthermore, traditional pesticides can be applied in a much more limited way geographically. Neonic pesticides can be applied in several ways. ${ }^{78}$ The most common form of systemic pesticide application is via seed or soil treatment. ${ }^{79}$ Traditional pesticides can be applied using the spray technique, and the leaves and stems of the plant can be specifically targeted. Systemic pesticides, however, affect the plant differently. First, often times the seed of the treated plant is soaked in the neonic. The neonics are then absorbed into the essential plant apparatus and are manifested in all physical parts of the plant throughout the entire growth process and for years to follow. Other ways that neonics can be applied include from the water source and by spraying. In both of these cases, the pesticides are absorbed into the physical plant apparatus and the

\footnotetext{
${ }^{77}$ Edwards, C. A. "Insecticide Residues in Soils." Reviews of Environmental Contamination and Toxicology Residue Reviews, 1966, 83-132.

${ }^{78}$ Bonmatin, J.-M., C. Giorio, V. Girolami, D. Goulson, D. P. Kreutzweiser, C. Krupke, M. Liess, E. Long, M. Marzaro, E. A. D. Mitchell, D. A. Noome, N. Simon-Delso, and A. Tapparo. "Environmental Fate and Exposure; Neonicotinoids and Fipronil." Environmental Science and Pollution Research Environ Sci Pollut Res 22, no. 1 (2014): 35-67.

${ }^{79}$ Bonmatin, J.-M., C. Giorio, V. Girolami, D. Goulson, D. P. Kreutzweiser, C. Krupke, M. Liess, E. Long, M. Marzaro, E. A. D. Mitchell, D. A. Noome, N. Simon-Delso, and A. Tapparo. "Environmental Fate and Exposure; Neonicotinoids and Fipronil." Environmental Science and Pollution Research Environ Sci Pollut Res 22, no. 1 (2014): 35-67.
} 
surrounding environment, such as the soil. Since systemic pesticides stay absorbed within environmental elements like the soil, agriculture planted later and pollinators living in and around the soil also absorb the leftover neonics. ${ }^{80}$ Moreover, the absorption into the environment can have indirect effects on areas far from the application site, "Environmental contamination occurs via a number of routes including dust generated during drilling of dressed seeds, contamination and accumulation in arable soils and soil water, runoff into waterways, and uptake of pesticides by nontarget plants via their roots or dust deposition on leaves." ${ }^{81}$ The scope and durability of pesticides is what is important here - and these are drastically increased when the pesticide is systemic. Systemic pesticides are a crucial element of the identity of the risk identified in Criterion (1). The scope and expansiveness of the hazard become magnified when the pesticide agent is systemic, and appropriate steps ought to be taken to evaluated and combat the complexities of the hazard.

\section{Criterion (2) concerns the dosage of the systemic pesticide (for purposes}

here, neonicotinoid) used. This is of particular importance because, as discussed in Criterion (1), the application of systemic pesticides can be very

\footnotetext{
${ }^{80}$ Pisa, L. W., V. Amaral-Rogers, L. P. Belzunces, J. M. Bonmatin, C. A. Downs, D. Goulson, D. P. Kreutzweiser, C. Krupke, M. Liess, M. Mcfield, C. A. Morrissey, D. A. Noome, J. Settele, N. Simon-Delso, J. D. Stark, J. P. Van Der Sluijs, H. Van Dyck, and M. Wiemers. "Effects of Neonicotinoids and Fipronil on Non-target Invertebrates." Environmental Science and Pollution Research Environ Sci Pollut Res 22, no. 1 (2014): 68-102.

${ }^{81}$ Bonmatin, J.-M., C. Giorio, V. Girolami, D. Goulson, D. P. Kreutzweiser, C. Krupke, M. Liess, E. Long, M. Marzaro, E. A. D. Mitchell, D. A. Noome, N. Simon-Delso, and A. Tapparo. "Environmental Fate and Exposure; Neonicotinoids and Fipronil." Environmental Science and Pollution Research Environ Sci Pollut Res 22, no. 1 (2014): 35-67.
} 
difficult to contain, which can ultimately drastically affect the amount and extent to which pollinators are affected. Any level of systemic pesticide use is harmful, but it is worth noting that misuse or uncontained use is quite common. Further, how potent is the substance? Systemic pesticides (of which neonicotinoids are a subgroup) are often highly concentrated and the toxicity lasts significantly longer than traditional pesticides do. Suchail et al. found that neonics are particularly harmful to bees when consumed orally, as compared to traditional pesticides ${ }^{82}$ Oral consumption is one of the most likely forms of consumption of neonics by bees because the pesticides manifest in the plant's nectar and pollen, which end up in honey - bees' main food source. Oral consumption isn't the only danger, however. Chronic exposure to less toxic levels are also detrimental to bee and hive health, "Death is not the only outcome from pesticide contamination. An amount of pesticide too small to kill a bee is referred to as a sublethal dose. At sublethal doses, chemicals may disrupt cognitive abilities, communication, various behaviors, and physiology. The ability for a honey bee colony to collect and store food depends on coordination and communication between workers. ${ }^{" 83}$ For example, when traditional, topical pesticides are applied, there is a few day window in which the toxicity is highest, which tapers out over the next few days. The effects of neonics affect

\footnotetext{
${ }^{82}$ Suchail S, Sousa G, Rahmani R, Belzunces LP. In vivo distribution and metabolisation of C-14imidacloprid in different compartments of Apis mellifera L. Pest Manag Sci. 2004;60:1056-1062.

${ }^{83}$ Hopwood, Jennifer et. al. "Are Neonicotinoids Killing Bees?." Xerces Society. Accessed November 17, 2015. http://ento.psu.edu/publications/are-neonicotinoids-killing-bees.
} 
plants and pollinators for extended periods of time, and can remain in the soil for years. ${ }^{84}$

\section{Criterion (3) calls for the determination of the level of exposure to}

surrounding areas. Aspects like duration and frequency of the exposure need to be measured. Again, the duration of exposure effects in systemic pesticides are exponentially higher than traditional non-systemic pesticides. It is imperative to question aspects like how long will the pesticide remain in the soil and the plant? And how long until effects are detectable in pollinators and other non 'pests'? The answer is for years. In many ways, this 'ability' is what separates neonics from traditional pesticides, "Neonicotinoids ... are among the most widely used pesticides in the world. Their popularity is largely due to their high toxicity to invertebrates, the ease and flexibility with which they can be applied, their long persistence, and their systemic nature, which ensures that they spread to all parts of the target crop." 85

In 2005, Bonmatin et. al performed studies on the application and accumulation of neonic pesticides, particularly focusing on residuals of

\footnotetext{
${ }^{84}$ Bonmatin, J.-M., C. Giorio, V. Girolami, D. Goulson, D. P. Kreutzweiser, C. Krupke, M. Liess, E. Long, M. Marzaro, E. A. D. Mitchell, D. A. Noome, N. Simon-Delso, and A. Tapparo. "Environmental Fate and Exposure; Neonicotinoids and Fipronil." Environmental Science and Pollution Research Environ Sci Pollut Res 22, no. 1 (2014): 35-67.

${ }^{85}$ Bonmatin, J.-M., C. Giorio, V. Girolami, D. Goulson, D. P. Kreutzweiser, C. Krupke, M. Liess, E. Long, M. Marzaro, E. A. D. Mitchell, D. A. Noome, N. Simon-Delso, and A. Tapparo. "Environmental Fate and Exposure; Neonicotinoids and Fipronil." Environmental Science and Pollution Research Environ Sci Pollut Res 22, no. 1 (2014): 35-67.
} 
Imidacloprid, the most commonly used systemic pesticide in the world. ${ }^{86}$

Concentrations were higher in soils that had been treated more than one year in a row, consistent with the theory that neonics accumulate in the soil over time. The use of Imidacloprid as seed-dressing induces residual contamination of soils. ${ }^{87}$ This long persistence in soils has already been depicted and can lead to the recovery of Imidacloprid by the next crops. ${ }^{88}$

Most tests utilized by the EPA traditionally test within a narrow timeframe for effects. However, many effects of systematic pesticides do not manifest within the narrow window of time studied by the EPA, thus producing an unreliable result. ${ }^{89}$ Moreover, the EPA's tests often do not test the harmfulness of the sub lethal effects of systemic pesticides on bees and other pollinators. Instead, the EPA generally concludes whether a pesticide is harmful based on whether the effects of the pesticide are lethal or not. David Mendes, Vice President of the American Beekeeping Association, warns us about the inability of the EPA's guidelines to provide a thorough understanding of the effects of neonics, particularly since pesticides' makeup have changed over the years (primarily by a shift to systemic pesticides like neonics). "EPA regulations

${ }^{86}$ Bonmatin, J.M., I. Moineau, R. Charvet, M.E. Colin, C. Fleche, and E.R. Bengsch. Environmental Chemistry. Chapter 44: Behaviour of Imidacloprid in Fields. Toxicity for Honey Bees. Springer, 2005.

${ }^{87}$ Bonmatin, J.M., I. Moineau, R. Charvet, M.E. Colin, C. Fleche, and E.R. Bengsch. Environmental Chemistry. Chapter 44: Behaviour of Imidacloprid in Fields. Toxicity for Honey Bees. Springer, 2005. P. 32, 36, 37

${ }^{88}$ Bonmatin, J.M., I. Moineau, R. Charvet, M.E. Colin, C. Fleche, and E.R. Bengsch. Environmental Chemistry. Chapter 44: Behaviour of Imidacloprid in Fields. Toxicity for Honey Bees. Springer, 2005.

${ }^{89}$ Vanishing of the Bees. Directed by Maryam Henein and George Langworthy. UK: Hive Mentality Films \& Hipfuel Films, 2009. DVD. 
deal with lethal dose to adult bees. Their perception is they've done their job, but there's a hole missing. When they change the nature of the pesticides, the mode of action, they needed to change the regulation, and that did not occur.."90 However, the threats faced by pollinators (particularly CCD for bees) is not caused by only lethal effects. In fact, the sub lethal effects of these systematic pesticides are the majority of the concern or threat: side effects of these pesticides include impaired navigation and compromised digestive and immune systems, which makes bees susceptible to pathogens they are otherwise immune to. ${ }^{91}$ This question is significant to the issue because the EPA only tests for immediate lethal effects, or within a window where the sublethal effects are not fully manifested, and thus are not taken into account when evaluating the risk of the use of neonicotinoids on pollinators. Most of the time, bees are not affected immediately, but instead become confused and weak after pollinating a flower that has been applied with a neonicotinoid agent. ${ }^{92}$. Systemic pesticides also damage the nerve and neurological systems in pollinators, often making them too confused and/or weak to return to their

\footnotetext{
${ }^{90}$ Vanishing of the Bees. Directed by Maryam Henein and George Langworthy. UK: Hive Mentality Films \& Hipfuel Films, 2009. DVD.

${ }^{91}$ Hopwood, Jennifer et. al. "Are Neonicotinoids Killing Bees?." Xerces Society. Accessed November 17, 2015. http://ento.psu.edu/publications/are-neonicotinoids-killing-bees. P. 11.

${ }^{92}$ Hopwood, Jennifer et. al. "Are Neonicotinoids Killing Bees?." Xerces Society. Accessed November 17, 2015. http://ento.psu.edu/publications/are-neonicotinoids-killing-bees. P. 11.
} 
hive. ${ }^{93}$ When the bees do successfully return to the hive after exposure to neonicotinoids, the pollen they deposit puts the rest of the hive at risk for the exposure (including the young, which are at peak susceptibility).

\section{Criterion (4) focuses on the projected impact on a particular ecosystem.}

This criterion is significant because it uses the first three criteria to provide a fuller, more informative picture of the effects of the use of neonics on the environment and on humans. This information allows a more comprehensive and ethical risk assessment to be made.

The use of neonic pesticides has an enormous effect on the population of pollinators. Whether the impact is lethal or sublethal, the populations continue to decline at rapid rates, giving rise to the need for action for pollinator protection. First, the lethal effects impact bees' population so that they cannot reasonably cultivate a hive habitat. A beehive is an intricate community through which they provide food, security, sanitation, and care for their young. ${ }^{94}$ Bees, like other living beings, exhibit symptoms of stress when their communities are out of balance.

Bees' intricate communication mechanisms are also severely disturbed when impacted by the sublethal effects of neonics (such as impaired cognitive

\footnotetext{
${ }^{93}$ Hopwood, Jennifer et. al. "Are Neonicotinoids Killing Bees?." Xerces Society. Accessed November 17, 2015. http://ento.psu.edu/publications/are-neonicotinoids-killing-bees. P. 11.

94 "The Colony and Its Organization." MAAREC Mid Atlantic Apiculture Research Extension Consortium RSS. 2010. Accessed August, 2016. https://agdev.anr.udel.edu/maarec/honey-bee-biology/the-colony-and-its-organization/.
} 
functioning that hinders communication, navigation, and immunity). ${ }^{95}$ When bees cannot effectively communicate food sources to the rest of their hive, the hive is greatly impacted through starvation and stress. When several bees cannot find their way back to the hive, the population dwindles. Further, neonic pesticides impact the physical health of the hive in two main ways. First, neonics often manifest within the pollen and nectar of a plant. Since pollen and nectar are collected on the body of the bee, the pollinators bring back these harmful substances attached to their body and into the hive. The younger bees who have not fully developed their immune systems (including larvae) come into contact with the pesticides and become diseased and even die. Second, the neonic pesticides break down healthy pollinators who have built up immune systems. These bees become diseased and/or susceptible to various threats like the Varroa mite. When otherwise healthy bees become infected by disease or pest and return to the hive, they carry with them the threat and expose the rest of the hive, hurting the population and immunity of the hive in this way as well.

These negative impacts have resulted in astronomical bee decline, with over $25 \%$ of the United States' bee population disappearing since $1990 .{ }^{96}$

Since bees have such a crucial impact on humans through providing

\footnotetext{
${ }^{95}$ Hopwood, Jennifer et. al. "Are Neonicotinoids Killing Bees?." Xerces Society. Accessed November 17, 2015. http://ento.psu.edu/publications/are-neonicotinoids-killing-bees.

${ }^{96}$ Chavarria, Gabriela. "Pollinator Conservation." Renewable Resources Journal, 2000.
} 
agricultural variation (and the nutritional component this provides) as well as ecosystemic balance and economic sustainability, humans are thus indirectly affected by neonics as well. Unhealthy and/or rapidly declining bee populations are increasingly unable to provide levels of pollination consistent with our agricultural and economic demands of a modern world facing issues of hunger. Current estimations label bees and other pollinators responsible for $30 \%$ of food supply worldwide. ${ }^{97}$ Economically, honeybees play a $\$ 14$ billion role, and play a role in an estimated $16 \%$ of flowering plant biodiversity outside of agriculture. ${ }^{98}$ More on the impacts of neonics on bees, the environment, and humans will be discussed in Criterion (5) next.

The first four criteria are used to provide more than just an efficient evaluation of the use of pesticides - they consider the effects on the health of the environment for its own sake, and the impact of environmental health on humans as well. This evaluation inherently contains a concern and admiration for environmental health and human life. Moreover, it gives us information so that we can more accurately balance the competing interests. Pesticides affect many elements of the environment, particularly depending on their makeup (whether they are systemic or not), the toxicity, etc. Therefore, the use of just one, or even some, of these criteria does not provide a complete picture of the effect of neonicotinoids on pollinators or the surrounding environment. These

\footnotetext{
97 "Protecting Pollinators from Pesticides." Oregon Department of Agriculture. 2014. Accessed August 11, 2015. http://library.state.or.us/repository/2014/201407011327512/.

98 "Forum-Bee Benefits to Agriculture." United States Department of Agriculture: AgResearch Magazine, March 2004. http://agresearchmag.ars.usda.gov/2004/mar/form.
} 
four criteria of Robson and Toscano's model ought to be combined with a fifth criterion that I outline below.

Criterion (5) is discussed separately because it gauges a different type of information: the comparative values. Criterion (5) is also what turns this risk assessment into an ethical one. The addition of criterion (5) into the ethical risk assessment framework is necessary to compare the values of the affected parties (humans, the environment, and pollinators) in order to determine the overall net gains and losses for each affected party. The inclusion of Criterion (5) moves the performance of the risk assessment beyond simply an assessment of the effects, to a more comprehensive value comparison. This assures an evaluation that is objective and takes all affected parties' net gains and losses into consideration. Moreover, the addition of criterion (5) is what turns a traditional risk assessment into an ethical one; currently, considerations or evaluations extend from solely the human realm into the realm of the environment. The advantage of the extent of ethical considerations to the environment is twofold: first, the environment (including bees and other pollinators, plants, etc.) is beneficial in and of itself. Second, extending ethical consideration to the environment is good for humans; the environmental effects discussed in this thesis have direct and real consequences on human comfort and health, such as agricultural variation and economic stability. These net 
gains and losses are then comparatively analyzed, which determines the best outcome overall, for both humans and the environment.

\section{Criterion (5) specifically calls for comparing the values of affected}

parties. Criteria 1-4 mostly focus on the negative effects of neonicotinoids. The addition of Criterion 5 brings in the utility of bees as well, or the positive effects of preventing harm to bees and other pollinators. This next section will use Criterion 5 to explore how the protection of/harm to pollinators impacts the net gains and losses of public health, the environment, economic stability, and ecosystemic longevity.

\section{The Utility of Bees}

Bees are crucial for crop and food production. Bees and other pollinators are responsible for the majority of crops we eat on a local, regional, national, and global level. Without bees, crops are required to be pollinated by hand, which is not as effective in terms of production or cost. Pollinators are responsible for approximately $75 \%$ of our flowering plants and crops like fruits 
and vegetables, including coffee, almonds, blueberries, and chocolate ${ }^{99}$.

Furthermore, we need pollinators in order for plants to produce fruits and seeds that feed other wildlife that is a vital part of both our diet and our ecosystem's balance. $^{100}$

Bees and other pollinators are an integral part of our economic system. Local, regional, national, and global economics are drastically affected by these pollinators, "In the United States pollination by honey bees directly or indirectly (e.g., pollination required to produce seeds for the crop) contributed to over $\$ 19$ billion of crops in 2010. Pollination by other insect pollinators contributed to nearly $\$ 10$ billion of crops in 2010."101

Because of bees' and other pollinators' integral role in our food and economic system, it is clear that there is a significant amount of utility gained through their existence, and a substantial, life-altering loss without them. Therefore, it is crucial to carefully evaluate potential threats to pollinators. If bees and other pollinators are killed off or the population continues to decrease at this rapid rate, we will not have means to pollinate crops and thus produce a large amount of agriculture for either feeding our families or economic

\footnotetext{
99 "Pollinators Home Page - U.S. Fish and Wildlife Service." Pollinators Home Page - U.S. Fish and Wildlife Service. Accessed August 10, 2015. http://www.fws.gov/pollinators/.

100 "Pollinators Home Page - U.S. Fish and Wildlife Service." Pollinators Home Page - U.S. Fish and Wildlife Service. Accessed August 10, 2015. http://www.fws.gov/pollinators/.

$100 \mathrm{http}: / /$ www.fws.gov/pollinators/

101 "Pollinators Home Page - U.S. Fish and Wildlife Service." Pollinators Home Page - U.S. Fish and Wildlife Service. Accessed August 10, 2015. http://www.fws.gov/pollinators/.

101 "Pollinators Home Page - U.S. Fish and Wildlife Service." Pollinators Home Page - U.S. Fish and Wildlife Service. Accessed August 10, 2015. http://www.fws.gov/pollinators/.
} 
sustainability. But taking a stance on this issue is more than an action; it sends a symbolic message to the rest of the world that the United States is ready to take this issue seriously. Moreover, both because the world today acts as a global economy in many ways, and also because this is a global ecological crisis, this issue needs to be taken on from a global level, with global cooperation; the United States, or any other country for that matter, cannot solve this issue alone. But one country's action can have a domino effect of encouraging other countries to become involved.

Coming together as a society would send a positive message globally about the urgency to become more involved in environmental issues now; the narrative needs to exist in environmental issues as they currently pertain to our ecosystems and society. The United States is seen as a major global player, and our willingness to take potential threats to ecosystemic longevity, agricultural variety, and economic stability could encourage other countries to stake a claim in environmental action as well. If political positions change, economic positions could follow, releasing the tight grip the market and industrial goals have on local, regional, national, and global economic agendas. Developing policy that serves the majority, as discussed, in many ways fail to address populations that are already disenfranchised and struggle with access to food. Eliminating neonic pesticides has the potential to eliminate the agricultural revolutions that come with it, like agricultural production on a scale large enough to potentially cater to these groups. While in some situations the 
populations that are already disenfranchised may remain in that situation, I argue that it is worth the cost to try to develop policy that benefits the population on the whole. To develop policy based on the minority populations would be unreasonable structurally and time-wise. The already rapidly declining population of pollinators is a situation that needs to be addressed in a time sensitive matter and in a way that makes the most sweeping changes initially.

It is worth considering that even if a potential fractional loss of crops by shifting to farming that does not use systemic pesticides, that crop yield is still more than what would occur without bees and other pollinators that are being wiped out, in large part due to the use of systemic pesticides, particularly neonics. Many flowering plants simply would not exist without healthy pollinator populations, "Bees and other insect pollinators which are necessary for the successful reproduction of most species of flowering plants, including agricultural crops, have been ignored by our preservation efforts..."102 Pollinators are a crucial component of agricultural variety and reproduction. Without a healthy pollinator population, many arguments of food production become moot.

A Utilitarian perspective can also provide criticism for this point; it can be argued that an increase in utility would be higher food production through the

\footnotetext{
102 Tepedino, V. J.. 1979. "THE IMPORTANCE OF BEES AND OTHER INSECT POLLINATORS IN MAINTAINING FLORAL SPECIES COMPOSITION". Great Basin Naturalist Memoirs, no. 3. Monte L. Bean Life Science Museum, Brigham Young University: 139-50. http://www.jstor.org/stable/23376607.
} 
use of agricultural technology like neonicotinoid pesticides. Higher food production means more people can be fed. In local, regional, national, and global levels, hunger is a persistent issue-an issue that could conceivably be addressed through higher food production that is possible through the use of neonic pesticides to prevent crop infestation. The use of neonic pesticides is in many ways revolutionary for the agricultural world, ensuring higher crop production and unprecedented convenience for these possible higher volumes. The top chemical companies that manufacture neonic pesticides in the United States formed a research coalition called Growing Matters in order to evaluate the benefits of neonic pesticides in United States agricultural production, "According the coalition, the new research shows that a loss of neonicotinoids would force growers to rely on multiple and older classes of insecticides. More foliar sprays of broad-spectrum insecticides would be used in place of targeted seed or soil treatments. Across some commodity crops evaluated, the study found that each pound of neonicotinoid lost would be replaced by nearly five pounds of older insecticides". ${ }^{103}$

For some, the use of systemic pesticides like neonics is the agricultural technology we need to address problems like world hunger. In his work, "Organic Farming and World Hunger," author David Allan discusses the Utilitarian justification for the use of non-organic farming methods. Allan speaks to the importance of proper nutritional value, and that using non-organic farming

103 "Ag Coalition Issues Reports Documenting the Benefits of Neonics." Agri Pulse, October 2014. http://www.agri-pulse.com/ag-coalition-issues-studies-benefits-neonics-10292014.asp. 
methods produce higher crop yield in a smaller space, "Any health or environmental benefit from organic non-animal farms is insignificant compared to a person's right to adequate nourishment. Any damage due to the pesticides of conventional non-animal farms is negligible in the need to feed those who suffer from famine." 104

Neonicotinoids were originally developed in the 1990's in response to other harmful pesticides being used, like DDT. To many, the use of neonics is seen as the answer to the problem of agricultural production and a way to address the ever present hunger issue -locally and globally.

On the other side, many argue that neonics are not only harmful in and of themselves, but can set off a chain reaction of negative environmental and agricultural issues down the proverbial road. These arguments establish that neonics actually increase pests' immunity to pesticide mitigation, which requires more and harsher chemicals to be used in the next round of pest management (spraying). A study used by the National Institute of Health further investigated these claims, finding an increase in pests meant to be reduced by the use of neonics, “... the population growth of spider mites increased from $30 \%$ to over $100 \%$ on neonicotinoid-treated plants in the greenhouse and by nearly $200 \%$ in the field experiment." ${ }^{105}$

\footnotetext{
${ }^{104}$ Allan, Davin. "Organic Farming and World Hunger - Literatured." Literatured. 2013. Accessed October 11, 2015. P. 1. http://literatured.com/organic-farming-and-world-hunger/. 105 Szczepaniec, Adrianna, Michael J. Raupp, Roy D. Parker, David Kerns, and Micky D. Eubanks. "Neonicotinoid Insecticides Alter Induced Defenses and Increase Susceptibility to Spider Mites in Distantly Related Crop Plants." PLOS ONE 8, no. 5 (2013).
} 
My response to Allan and other thinkers that use Utility Theory as a justification for farming practices that use systemic pesticides is that this calculation only includes immediate effects to humans, and does not consider effects far enough in the future. Effects on humans caused by the rapid decline of pollinators come in many forms outside food production, such as economic stability, agricultural variety and the nutritional components this carries, and ecosystemic longevity._Moreover, Utilitarians that consider food production as the main component of their calculation, I argue, are not properly applying Utilitarianism. As discussed in chapter 1, Jeremy Bentham regarded duration and intensity of the net 'gains' and 'losses' as a fundamental aspect of the calculation. Taking Bentham's elements of duration and intensity into account is an important step to see the utility in placing a ban on neonics: in the current infrastructure, the benefits are distributed among the few chemical companies that produce and manufacture these harmful chemicals, along with farmers and to those benefitting from increased food production. Next, I will provide a brief discussion on how the proper application of Utilitarianism actually discredits the use of neonics.

The proper application of Utilitarianism, I argue, goes farther than the arguments of those who try to use Utilitarianism in support of the use of neonics. Thinkers like Nicholas P. Guehlstorf also discusses the importance of taking into account factors like intensity and duration, particularly when calculating the negative effects, “... understanding the magnitude of danger 
posed to human life, public health, and affected ecosystems are at the foundation of most environmental programs." ${ }^{\text {106 }}$ Instead, I argue that it is also equally important to consider longevity in food production when considering utility levels. The use of neonicotinoids may provide an increase in food production (the exact yield has been discussed previously), but the longevity of the use of neonicotinoids is short-lived. The continuous use of neonicotinoids may heavily contribute to the decline of pollinators, which would ultimately result in a significant decrease in food production and in the agricultural variation of the food produced. Accordingly, it seems as though even if neonics may immediately increase crop production, it is not a sustainable method to do so.

The inherent calculative apparatus of Utilitarianism ought to be applied to future consequences as well. Gifford Pinchot, a pioneer in combining environmental ethics and utilitarianism, coined the term 'conservation ethic' for natural resources. Pinchot rallied around the importance of responsible resource allocation and management. In "The Fight for Conservation," Pinchot discusses that while present generations are the primary concern, it is important to be concerned with future generations as well. ${ }^{107}$ Moreover, Pinchot defines the very notion of conservation as utilitarian in nature, but with an eye

\footnotetext{
${ }^{106}$ Guehlstorf, Nicholas P. "The Utilitarian Assessment." The International Library of Environmental, Agricultural and Food Ethics The Political Theories of Risk Analysis, 2004, 45-75.

${ }^{107}$ Pinchot, Gifford. The Fight for Conservation. Seattle: University of Washington Press, 1967. p. 43
} 
for the future as well, "Conservation means the greatest good to the greatest number for the longest time. Conservation advocates the use of foresight, prudence, thrift, and intelligence in dealing with our own private affairs." ${ }^{108}$ This quote essentially captures the heart of Utility Theory's response to those who want to use the theory to support the use of neonicotinoids through the goal of increased food production. It captures the realization that the decline of pollinators affects humans in so many indirect ways. As noted earlier, bees and other pollinators are responsible for an estimated one-third of each mouthful. A potentially reduced crop yield that maintains agricultural variation and eco systemic balance, I argue, outweighs a higher crop yield of fewer fruits, vegetables, and staple foods. Bees are an integral component of food production. This counterargument, combined with the statistics that provide a clearer picture as to how much crop yield is potentially lost is, I argue, convincing enough to show that Utility Theory ought to be used in support of the ban of neonicotinoids and that any subsequent minor crop yield loss is worth the payoff for the greater good (both presently and in the future).

There are also many indirect consequences (positive or negative) that are inherent in the survival or demise of pollinators. In, "The Endangered Species Act as a Tool to Conserve Biological Diversity," Andrew R. Solow and Stephen Polasky use a Utilitarianism approach to ecological conservation in general. The authors discuss these indirect consequences of environmental

${ }^{108}$ Pinchot, Gifford. The Fight for Conservation. Seattle: University of Washington Press, 1967. p. 48 
health. They call these indirect consequences 'ecosystem services' which include, "...the provision of habitat for commercially important species and the maintenance of water quality through uptake of nutrients.... The issue then becomes the extent to which preventing the extinction of individual species contributes to ecosystem conservation." ${ }^{109}$ This is an important point, because the health of pollinators affects more than the agricultural variation and economic stability at stake if pollinators continue to decline. Systemic pesticides can remain in the soil for years, make their way into water sources, and can remain in the plant that is ingested by the consumer.

I argue that it is of the utmost importance to look at the use or ban of neonics in the long run, and how their use or ban can affect several other indirect elements. The Harvard School of Health, Center for Health and the Global Environment also contends with the importance of maintaining ecosystemic variety and longevity, as the cultivation and flourishing of many plants and animals depend on one another, "What is also not appreciated is that modern crops and livestock vitally depend on hundreds of thousands of other species, including insects and birds that pollinate crops and feed on pests, and numerous microbial species that live on and in plants and animals, and that are especially critical to survival."110

\footnotetext{
${ }^{109}$ Solow, Andrew R., and Stephen Polasky. "The Endangered Species Act as a Tool to Conserve Biological Diversity." CHOICES, Fall 1999. P.2 http://ageconsearch.umn.edu/bitstream/131694/2/BiologicalDiversity.pdf.

110 "Biodiversity and Agriculture." Biodiversity and Agriculture. Accessed July 15, 2015. http://www.chgeharvard.org/topic/biodiversity-and-agriculture.
} 
The movement against pesticides should be accompanied by a proclivity toward organic farming practices and an interest in devoting resources toward long term solutions for pest management that compliment the ecosystems.

Taking steps to protect bees and other pollinators in the face of evidentiary uncertainty is a prudent approach to the health of pollinators, the environment and its ecosystems, and human life. Moreover, as noted, it is important to plan for future generations and for the longevity of crop survival, which will be exponentially more at risk as bees tend to decline in population.

The five criteria I have established here are essential to providing a complete ethical risk assessment of the use of neonicotinoids on environmental and human health, particularly pertaining to pollinators. Criteria 1-4 are essential in determining the toxicity and lingering presence of neonic pesticides Criterion 5 calls for a value assessment that is both comparative and complimentary. These values can contribute to the overall picture of the effect of neonics on environmental and human health, which encapsulates the important pragmatic and societal elements to policy changes. In fact, Robson and Toscano discuss the impacts of environmental ethical risk assessment on policies like legislative bans on neonics, “... the exploration of risk can help inform priority setting, policy making, and decision making at global, national, regional, and local levels." (p.3). ${ }^{111}$

${ }^{111}$ Robson, Mark G., and William A. Toscano. Risk Assessment for Environmental Health. Vol. 2. Public Health/Environmental Health. John Wiley \& Sons, 2007. 
The purpose of chapter 2 was to outline what an ethical risk assessment would look like as applied to a case study of the use of neonics and their effects on pollinators. I argued that these five criteria encourage a critical evaluation of the EPA's current risk assessment model and a deeper investigation into the parameter (direct and indirect) of the use of neonics on environmental and public health. This critical evaluation concluded that the EPA's current risk assessment model does not provide adequate protection of environmental and/or human health. Instead, an ethical risk assessment should be performed that further evaluates the effects of neonicotinoids on pollinators. Further, the five criteria can provide theoretical guidelines for future environmental policy development, particularly when faced with policy issues that have little or no evidentiary certainty to the risks posed.

\section{CHAPTER THREE: CONCLUSION}

I began this thesis with the goal to determine an appropriate policy guideline in the face of evidentiary uncertainty. In order to provide such a policymaking guideline, I have developed a set of five criteria based in Utilitarianism. I ultimately argue that this set of five criteria must be considered in order to constitute an ethical risk assessment. An ethical risk assessment is 
advisable in the case of evidentiary uncertainty because it allows an evaluation of how high the stakes are. Because of the potentiality of high stakes risk in the face of this uncertainty, we must consider them much more carefully, especially in terms of policymaking. I develop this set of five criteria based on existing literature in combination with those I find important based on my own research.

My research made it more clear that the testing mechanisms used to evaluate the effects of neonics are narrow in scope and do not provide a complete picture of these effects. In fact, as much as $96 \%$ of studies done evaluating the effects of pesticides are performed in controlled conditions, leaving little conclusive evidence to the actual effects on insects, honeybees and other pollinators. ${ }^{112}$ Moreover, while these pesticides may not be as directly harmful to larger animals, a potential massive die off of insects and pollinators drastically and directly would affect the food chain for these animals, ultimately depleting many of their sources of food.

While the main conclusion I reach is that neonics ought to be banned, I fully support further research being performed once a ban is in place. While outlining what the approach to this further research might look like is outside the scope of this thesis, I think it is important not only for more research to be performed, but that this research is done in an objective manner by neutral

112 "Scientists Warn That a Widely Used Pesticide Could Be Worse for Bees Than DDT." TakePart. Accessed March 11, 2016. http://www.takepart.com/article/2014/06/24/areneonicotinoids-new-ddt-bees-and-other-wildlife. ; "WORLDWIDE INTEGRATED ASSESSMENT ON SYSTEMIC PESTICIDES." The Task Force on Systemic Pesticides. June 2014. http://www.tfsp.info/wp-content/uploads/2014/06/WIA-MB.pdf. 
parties. This research also ought to be performed largely in field conditions, where nuances of ecosystemic variation and other environmental influences are accounted for. This will provide a more thorough and complete approach toward information used in policy development.

This thesis has focused on a particular question spawned from the passage of recent legislative actions banning the use of neonicotinoid pesticides: Are the legislative steps banning the use of pesticides harmful to pollinators justified? I define 'justified' as constituting the appropriate and necessary action in order to conserve pollinator population to an extent that preserves the elements like ecosystemic balance, agricultural variety, and economic stability. I argue that the EPA standards currently in use are insufficient for adequate evaluation of the effects of neonicotinoids on pollinators. The EPA tests don't provide sufficient information for an ethical risk assessment, which I argue is necessary given the inconclusive nature of the evidence and the high stakes. The deficient standards available from the EPA render a need for additional measures to be taken to protect bees and other pollinators against the use of neonicotinoid pesticides. Through my application of an ethical risk assessment and thus an application of Utility Theory, I conclude that legislative bans on neonics are justified. Essentially, I arrive at this conclusion because of the important contributions the pollinator population makes to ecosystemic longevity, agricultural variation (and the nutritional component this provides) and economic stability. In many ways, bees and other 
pollinators increase the utility of the environment (including pollinators) and increase the utility of humans. The potential risks that neonics introduce are serious enough to justify policy banning their use. Furthermore, the utility of the environment/pollinators directly impacts the utility of humans.

I argue that Utilitarianism is the most appropriate approach for evaluating difficult policy issues like those posed by neonics. Utilitiarianism is the best time-sensitive, politically encompassing structure by which to use as a foundation to develop policy for the greatest number. Utilitarianism is also unique in its approach toward ethics because it takes into account ethics not only in terms of anthropocentric values. Utilitarianism as the foundation for the ethical risk assessment also considers the value of the environment and its inhabitants for its own sake.

The reliance on Utilitarianism provides a foundation for the five criteria that make up the ethical risk assessment. Each criterion is in and of itself an important consideration, but the combination of them makes my approach unique and inherently 'ethical'. Criteria 1-4 focus on the identification of the potential hazard: (1) consider the harmful elements, (2) measure the extent and significance (such as toxicity) of the hazard, (3) the duration and/or frequency of exposure to the hazard, and (4) the risk assessment of the projected impact of the hazard on the environment, humans, etc. ${ }^{113}$ Criterion (5) is based on a comparison of values and parties involved. It is in these criteria that the

${ }^{113}$ Robson, Mark G., and William A. Toscano. Risk Assessment for Environmental Health. Vol. 2. Public Health/Environmental Health. John Wiley \& Sons, 2007. P. 34-35. 
essential 'ethical' component rests. Criterion (5) embodies an ethical comparison of the political, social, economic, and health effects of an evaluated agent(s).

Utilitarianism serves more than a realization of Criterion (5) in this thesis, however. Utilitarianism provides a useful framework to gauge effects and the risk assessment of pesticides on pollinators in three key ways: first, utilitarianism provides a workable framework for how to compare, decipher, and apply information used in the ethical risk assessment. Second, Utilitarianism considers notions of society, democracy, and the greater good in the context of comparative values. This ends up inevitably including human health, the environment, and pollinator health, as it is all essentially connected. This thesis establishes the interconnectedness, and thus impact, of the actions or effects of one agent on another. For example, the negative effects absorbed by pollinators can lead to disruption in many seemingly unrelated channels like agricultural variety or even economic stability. Moreover, Utilitarianism maintains the ethical parameters of the utility of bees and other pollinators both in and of themselves and in congruence with the rest of the channels discussed here. Third, inherent in Utilitarianism is a calculative apparatus by which to most effectively realize Criterion (5). Utilitarianism is also able to add a layer of political science to environmental ethical risk assessment. Generally in existing environmental risk assessments, political science plays a minimal or nonexistent role. 
In Chapter 2 I apply my ethical risk assessment. The five criteria that make up an ethical risk assessment establish that neonics have profound and lasting impacts on pollinator populations. The decline of pollinators in turn has serious effects on many aspects of everyday life including ecosystemic longevity, agricultural variation, and economic stability. Application of the ethical risk assessment reaches the conclusion that the level of harm/risk posed to bees and other pollinators by the use of neonicotinoid pesticides makes their continued use an overly risky option for crop production and pest control. Bees and other pollinators provide too crucial of a role in our environment, agriculture, society, and economic structure to allow the use of neonic pesticides. It is the combination of the utility of bees with the existing evidence of the potential of harm that justifies the ban of neonicotinoid pesticides. Therefore, I argue, the bans that have been enacted against their use are justified and should be implemented on a regional or federal scale. That is, further bans are ethically justified.

Some critics argue that the agricultural convenience and higher crop production make the risks of neonic pesticides worth the reward. To these critics I respond that the importance of maintaining our ability to produce a majority of our food must remain the priority. In his book "Choices: An Introduction to Decision Theory," ${ }^{114}$ Michael D. Resnik discusses how important it is to take into account the risk in relation to other risks, factors, and outcomes. "In a decision under risk

${ }^{114}$ Resnik, Michael D. Choices: An Introduction to Decision Theory. Minneapolis: University of Minnesota Press, 1987. 
it is often not enough to know that you prefer one outcome to another; you might also need to know whether you prefer an outcome enough to take the risks involved in obtaining it." That is, comparatively, losing some crops to the use farming practices that do not employ the use of neonics still ranks much more preferably to losing our ability to agriculturally produce for nutritional and/or economic purposes. If we continue to see a decline in the population of honeybees and other pollinators, we are going to be faced with an inability to agriculturally produce in the same way we have been. While the discussion of organic farming practices and the benefits (and shortcomings) are outside the scope of this paper, there is research that suggests the ability of organic farming practices to sustain global food needs, at least in comparison to the levels of food production possible with a significantly inhibited pollinator population. In fact, studies like the one performed at the Research Institute for Organic Agriculture in Switzerland unveiled that organic farms yield $20 \%$ less of crops over a 20 year span when compared to farms that use pesticides and herbicides ${ }^{115}$. By itself, this $20 \%$ can seem like an astronomical number with sweeping global effects of our ability to produce food and feed populations. However, it is important to compare this $20 \%$ decrease in crop production to a higher production with significantly less agricultural variation (and the nutritional consequences that can carry). Essentially, $80 \%$ of something is better than $100 \%$ of a drastically decreased spectrum of available fruits, vegetables, and flowering plants.

115 "Can Organic Farming Feed Us All?" Can Organic Farming Feed Us All? Accessed September 5, 2015. http://www.worldwatch.org/node/4060. 
Moreover, according to many studies, organic food is also more nutrient dense, so crop production is not something than can be measured strictly in numbers, "A majority of well-designed studies comparing nutrient density (milligrams of a given nutrient per kilogram of food) in organically and conventionally produced fruits and vegetables show modest to moderately higher concentrations of most nutrients in organic produce." 116

Moreover, as stated previously, this is a global problem. Bees and other pollinators' populations are drastically decreasing everywhere. Accordingly, the risks of neonics are serious enough to justify prohibition. The increase of objectively performed research by neutral parties in more realistic conditions ought to be pursued after the ban is enacted. The proper application of Utilitarianism, which includes intensity and duration, renders neonics as posing too high of a risk to bees and other pollinators to make their application worth continuing.

I end this thesis in support of the bans that have been placed on the use of neonicotinoids, and recommend they be implemented federally.

\footnotetext{
${ }^{116}$ Benbrook, Charles. "The Impacts of Yield on Nutritional Quality: Lessons from Organic Farming." HortScience, 12-14, 44, no. 1 (February 2009). http://hortsci.ashspublications.org/content/44/1/12.full.
} 


\section{Sources Cited}

"Ag Coalition Issues Reports Documenting the Benefits of Neonics." Agri Pulse, October 2014. http://www.agri-pulse.com/ag-coalition-issues-studiesbenefits-neonics-10292014.asp.

"Biodiversity and Agriculture." Biodiversity and Agriculture. Accessed July 15, 2015. http://www.chgeharvard.org/topic/biodiversity-and-agriculture.

"Can Organic Farming Feed Us All?" Can Organic Farming Feed Us All? Accessed September 5, 2015. http://www.worldwatch.org/node/4060.

"Forum-Bee Benefits to Agriculture." United States Department of Agriculture: AgResearch Magazine, March 2004. http://agresearchmag.ars.usda.gov/2004/mar/form. 
"Garden City of Alaska" Passes Comprehensive Pesticide Ordinance, Bans BeeToxic Pesticides." Beyond Pesticides: Daily News Blog, September 25, 2014. http://beyondpesticides.org/dailynewsblog/2014/09/garden-city-ofalaska-passes-comprehensive-pesticide-ordinance-bans-bee-toxicpesticides/.

"How We Assess Risks to Pollinators." EPA United States Environmental Protection Agency. United States Environmental Protection Agency, n.d. Web. 9 Aug. 2015. $<$ http://www.epa.gov/pollinator-protection/how-we-assess-riskspollinators $>$.

"Minnesota Passes Bill to Label Garden Plants for Pollinators." Beyond Pesticides: Daily News Blog, May 21, 2014.

http://beyondpesticides.org/dailynewsblog/2014/05/minnesota-passes-billto-label-garden-plants-for-pollinators/.

"Petitioners v. U.S. Environmental Protection Agency." United States Court of Appeals for the Ninth Circuit: Case 13-72346, September 2015 http://earthjustice.org/sites/default/files/files/sulfoxaflor-opinion.pdf.

"Pollinators Home Page - U.S. Fish and Wildlife Service." Pollinators Home Page - U.S. Fish and Wildlife Service. Accessed August 10, 2015. http://www.fws.gov/pollinators/.

"Protecting Pollinators from Pesticides." Oregon Department of Agriculture. 2014. Accessed August 11, 2015. http://library.state.or.us/repository/2014/201407011327512/.

"Scientists Warn That a Widely Used Pesticide Could Be Worse for Bees Than DDT." TakePart. Accessed March 11, 2016.

http://www.takepart.com/article/2014/06/24/are-neonicotinoids-new-ddtbees-and-other-wildlife.

"Seattle Joins the Growing List of Cities to Ban Bee-Killing Pesticides." Organic Consumers, September 2014. https://www.organicconsumers.org/news/seattle-joins-growing-list-citiesban-bee-killing-pesticides. 
"Summary." National Research Council. Status of Pollinators in North America. Washington, DC: The National Academies Press, 2007.

"The Colony and Its Organization." MAAREC Mid Atlantic Apiculture Research Extension Consortium RSS. 2010. Accessed August, 2016. https://agdev.anr.udel.edu/maarec/honey-bee-biology/the-colony-and-itsorganization/.

"WORLDWIDE INTEGRATED ASSESSMENT ON SYSTEMIC PESTICIDES." The Task Force on Systemic Pesticides. June 2014. http://www.tfsp.info/wp-content/uploads/2014/06/WIA-MB.pdf.

Allan, Davin. "Organic Farming and World Hunger - Literatured." Literatured. 2013. Accessed October 11, 2015. http://literatured.com/organic-farmingand-world-hunger/.

Bailes, Emily J., Jeff Ollerton, Jonathan G. Pattrick, and Beverly J. Glover. "How Can an Understanding of Plant-Pollinator Interactions Contribute to Global Food Security." Current Opinion in Plant Biology 26 (August 2015): 72-79.

http://www.sciencedirect.com.proxy.lib.pdx.edu/science/article/pii/S136952 6615000849 .

Baker, Susan, Katarina Eckerberg, and Anna Zachrisson. Political Science and Ecological Restoration 23, no. 3 (October 11, 2013): 509-24.

Benbrook, Charles. "The Impacts of Yield on Nutritional Quality: Lessons from Organic Farming." HortScience, 12-14, 44, no. 1 (February 2009). http://hortsci.ashspublications.org/content/44/1/12.full.

Bentham, Jeremy. An Introduction to the Principles of Morals and Legislation. Oxford: Clarendon Press. 1907. Library of Economics and Liberty [Online] available from http://www.econlib.org/library/Bentham/bnthPML1.html

Blacquiere, Tjeerd, Guy Smagghe, Cornelis van Gestel, and Veerle Mommaerts. "Neonicotinoids in bees: a review on concentrations, sideeffects and risk assessment." Ecotoxicology 21, no. 4 (May 2, 2012): 97392.

Bonmatin, J.-M., C. Giorio, V. Girolami, D. Goulson, D. P. Kreutzweiser, C. Krupke, M. Liess, E. Long, M. Marzaro, E. A. D. Mitchell, D. A. Noome, N. Simon-Delso, and A. Tapparo. "Environmental Fate and Exposure; 
Neonicotinoids and Fipronil." Environmental Science and Pollution Research Environ Sci Pollut Res 22, no. 1 (2014): 35-67.

Bonmatin, J.M., I. Moineau, R. Charvet, M.E. Colin, C. Fleche, and E.R. Bengsch. Environmental Chemistry. Chapter 44: Behaviour of Imidacloprid in Fields. Toxicity for Honey Bees. Springer, 2005.

Breez, Tom D. et. al. "Agricultural Policies Exacerbate Honeybee Pollination Service Supply-Demand Mismatches Across Europe." PLOS One (January 8, 2014).

http://journals.plos.org/plosone/article?id=10.1371/journal.pone.0082996\#r eferences.

Chavarria, Gabriela. "Pollinator Conservation." Renewable Resources Journal, 2000.

Cothern, C. Richard. Handbook for Environmental Risk Decision Making: Values, Perceptions, and Ethics. CRC Press LLC, 1996.

Demas, A, and K Kuivila. Insecticides Similar to Nicotine Widespread in Midwest. United States Geological Survey, 24 July 2014. Web. 17 Sept. 2017.

<http://www.usgs.gov/newsroom/article.asp?ID=3941\#.Vskb3c5Rfww>.

Dwyer, Marge. "Study strengthens link between neonicotinoids and collapse of honey bee colonies." Harvard School of Public Health. N.p., May 2014. Web. 20 Aug. 2015. <http://www.hsph.harvard.edu/news/pressreleases/study-strengthens-link-between-neonicotinoids-and-collapse-ofhoney-bee-colonies/>.

Edwards, C. A. "Insecticide Residues in Soils." Reviews of Environmental Contamination and Toxicology Residue Reviews, 1966, 83-132.

Elbert, Alfred et. al. "Applied aspects of neonicotinoid uses in crop protection." Pest Management Science 64, no. 11: 1099-105.

EPA United States Environmental Protection Agency. N.p., n.d. Web. 20 Feb. 2016. <http://www.epa.gov/pesticide-registration/data-requirements>.

Evans, RW, ACY Hsiau, PJ Dennison, A. Patterson, and B. Jalaludin. "Water Fluoridation in the Blue Mountains Reduces Risk of Tooth Decay." Australian Dental Journal 54, no. 4 (December 2009): 368-73. 
Gallai, Nicola, Jean-Michel Salles, Josef Settele, and Bernard E. Vaissiere. "Economic Valuation of the Vulnerability of World Agriculture Confronted with Pollinator Decline." Ecological Economics 68, no. 3 (January 15, 2009): 810-21.

Geranios, Nicholas K. "Spokane Bans Chemical That May Kill Bees." The Seattle Times, July 4, 2014. http://www.seattletimes.com/seattlenews/spokane-bans-chemical-that-may-kill-bees/.

Goulson, Dave. "REVIEW: An overview of the environmental risks posed by neonicotinoid insecticides." Journal of Applied Ecology 50, no. 4 (June 13, 2013): 977-87.

Guehlstorf, Nicholas P. "The Utilitarian Assessment." The International Library of Environmental, Agricultural and Food Ethics The Political Theories of Risk Analysis, 2004, 45-75.

Hopwood, Jennifer et. al. "Are Neonicotinoids Killing Bees?." Xerces Society. Accessed November 17, 2015. http://ento.psu.edu/publications/areneonicotinoids-killing-bees.

Hopwood, Jennifer et. al. "Are Neonicotinoids Killing Bees?." Xerces Society. Accessed November 17, 2015. http://ento.psu.edu/publications/areneonicotinoids-killing-bees. P. 11.

House, Kelly. "Oregon Bans the Use of Bee-Killing Insecticides on Linden Trees." The Oregonian, February 27, 2015. http://www.oregonlive.com/environment/index.ssf/2015/02/oregon_bans_u se_of_bee-killing.html.

Hover over the menu items to see examples of what we can do.

James D. Ellis, Jay D. Evans \& Jeff Pettis (2010) Colony losses, managed colony population decline, and Colony Collapse Disorder in the United States, Journal of Apicultural Research, 49:1, 134-136

Johnson, Renee. "Honey Bee Colony Collapse Disorder." Federation of American Scientists. (January 7 2010) 8. https://fas.org/sgp/crs/misc/RL33938.pdf.

Kaplan, Kim. "Honey Bee Health and Colony Collapse Disorder." USDA. Accessed September 15, 2015. http://www.ars.usda.gov/News/docs.htm?docid=15572\#public.

Kaplan, Kim. "Honey Bee Health and Colony Collapse Disorder." USDA. Accessed September 15, 2015.http://www.ars.usda.gov/News/docs.htm?docid=15572\#public. 
Krischik, Vera. "Protecting bees and beneficial insects from systemic insecticides applied in landscapes." University of Minnesota Extension. University of Minnesota, 24 July 2014. Web. 21 Aug. 2015. $<$ http://www.extension.umn.edu/garden/plant-nursery-health/protectingbees-beneficial-insects-systemic-insecticides/docs/protecting-bees-frominsecticides.pdfs.

LaJeunesse, Sara. "Rapid increase in neonicotinoid insecticides driven by seed treatments." Penn State News, April 2, 2015. http://news.psu.edu/story/351027/2015/04/02/research/rapid-increaseneonicotinoid-insecticides-driven-seed-treatments.

Lecture, The Loss of Ecosystem Services as a Result of Colony Collapse Disorder. April 30, 2105. http://digitalcommons.colby.edu/clas/2015/program/26/

Mill, John Stuart. Utilitarianism. Longmans, Green, Reader, and Dyer, 1871.

Miller, G. Tyler, and Scott Spoolman. Sustaining the Earth. 11th ed. N.p.: Cengage Learning, 2013. 97.

N.H. Lampkin, S. Padel (Eds.), The Economics of Organic Farming, CAB International, Wallingford, UK (1994), pp. 201-222

National Research Council, "Status of Pollinators in North America," The National Academies Press, Washington, D.C., 2007, www.nap.edu/catalog/11761/status-of- pollinators-in-north-america; Holden, C., "Report warns of looming pollination crisis in North America," Science, 314, pp. 397, October 20, 2006, www.sciencemag.org/ content/314/5798/397.

Newbrun, Ernest. "The Safety of Water Fluoridation." The Journal of the American Dental Association 94, no. 2 (February 1977): 301-04.

O'Brien, Councilmember. Seattle Council Connection. http://council.seattle.gov/2014/09/25/council-bans-neonicotinoidpesticides-on-city-land-2/.

Pinchot, Gifford. The Fight for Conservation. Seattle: University of Washington Press, 1967. p. 43 
Pinchot, Gifford. The Fight for Conservation. Seattle: University of Washington Press, 1967. p. 48

Pisa, L. W., V. Amaral-Rogers, L. P. Belzunces, J. M. Bonmatin, C. A. Downs, D. Goulson, D. P. Kreutzweiser, C. Krupke, M. Liess, M. Mcfield, C. A. Morrissey, D. A. Noome, J. Settele, N. Simon-Delso, J. D. Stark, J. P. Van Der Sluijs, H. Van Dyck, and M. Wiemers. "Effects of Neonicotinoids and Fipronil on Non-target Invertebrates." Environmental Science and Pollution Research Environ Sci Pollut Res 22, no. 1 (2014): 68-102.

Resnik, Michael D. Choices: An Introduction to Decision Theory. Minneapolis: University of Minnesota Press, 1987.

Robson, Mark G., and William A. Toscano. Risk Assessment for Environmental Health. Vol. 2. Public Health/Environmental Health. John Wiley \& Sons, 2007.

Robson, Mark G., and William A. Toscano. Risk Assessment for Environmental Health. Vol. 2. Public Health/Environmental Health. John Wiley \& Sons, 2007. P. 34-35.

Robson, Mark G., and William A. Toscano. Risk Assessment for Environmental Health. Vol. 2. Public Health/Environmental Health. John Wiley \& Sons, 2007. P 5.

Sarich, Christina. "Win! U.S. Fish \& Wildlife Service to Ban Use of Bee, Bird and Butterfly-Killing Neonicotinoids." Nation of Change, July 29, 2014. http://www.nationofchange.org/win-us-fish-wildlife-service-ban-use-beebird-and-butterfly-killing-neonicotinoids-1406642902.

Sass, Jennifer, and Mae Wu. "Superficial Safeguards: Most Pesticides Are Approved by Flawed EPA Process." Natural Resources Defense Council: Issue Brief. National Resources Defense Council, n.d. Web. 9 July 2015. $<$ http://www.nrdc.org/health/pesticides/files/flawed-epa-approval-processIB.pdf>.

Solow, Andrew R., and Stephen Polasky. "The Endangered Species Act as a Tool to Conserve Biological Diversity." CHOICES, Fall 1999.

http://ageconsearch.umn.edu/bitstream/131694/2/BiologicalDiversity.pdf.

Szczepaniec, Adrianna, Michael J. Raupp, Roy D. Parker, David Kerns, and Micky D. Eubanks. "Neonicotinoid Insecticides Alter Induced Defenses and Increase Susceptibility to Spider Mites in Distantly Related Crop Plants." PLoS ONE 8, no. 5 (2013). 
Tepedino, V. J.. 1979. "THE IMPORTANCE OF BEES AND OTHER INSECT POLLINATORS IN MAINTAINING FLORAL SPECIES COMPOSITION". Great Basin Naturalist Memoirs, no. 3. Monte L. Bean Life Science Museum, Brigham Young University: 139-50. http://www.jstor.org/stable/23376607.

Trumble, John T. "The Dependence of Crops for Pollinators and the Economic Value of Pollination in Brazil." Journal of Economic Entomology, May 4, 2015.

USDA 2012 Report on the National Stakeholders Conference on Honey Bee Health. October 15-17,2012.

USEPA. 2012. White Paper in Support of the Proposed Risk Assessment Process for Bees. Submitted to the FIFRA Scientific Advisory Panel for Review and Comment September $11-14,2012$. Office of Chemical Safety and Pollution Prevention Office of Pesticide Programs Environmental Fate and Effects Division, Environmental Protection Agency, Washington DC; Environmental Assessment Directorate, Pest Management Regulatory Agency, Health Canada, Ottawa, CN; California Department of Pesticide Regulation http://www.regulations.gov/\#!documentDetail;D=EPA-HQ-OPP-20120543-0004

van der Sluijs, Jeroen P., Noa Simon-Delso, Dave Goulson, Laura Maxim, JeanMarc Bonmatin, and Luc P. Belzunces. "Neonicotinoids, Bee Disorders and the Sustainability of Pollinator Services." Current Opinion in Environmental Sustainability 5, no. 3-4 (September 2013): 293-305.

vanEngelsdorp, Dennis et. al. "Colony Collapse Disorder: A Descriptive Study." PLOS One (August 2009). Accessed October 7, 2015. http://journals.plos.org/plosone/article?id=10.1371/journal.pone.0006481.

Vanishing of the Bees. Directed by Maryam Henein and George Langworthy. UK: Hive Mentality Films \& Hipfuel Films, 2009. DVD.

Velasquez, Manuel, Claire Andre, Thomas Shanks, and Michael J. Myer. "Calculating Consequences: The Utilitarian Approach to Ethics." Calculating Consequences:The Utilitarian Approach to Ethics 2, no. 1 (1989).

Walsh, Bryan. "Beepocalypse Redux: Honeybees Are Still Dying - and We Still Don’t Know Why." Time Magazine, May 7, 2013 
http://science.time.com/2013/05/07/beepocalypse-redux-honey-bees-are-stilldying-and-we-still-dont-know-why/.

Whitlock, Jared. "Encinitas to Test Pesticide-Free Park." Encinitas Advocate, June 15, 2015.

http://www.encinitasadvocate.com/news/2015/jun/15/encinitas-pesticideparks-bees/.

Wines, Michael. "Mystery Malady Kills More Bees, Heightening Worry on Farms." New York Times, March 28, 2013. http://www.nytimes.com/2013/03/29/science/earth/soaring-bee-deaths-in2012-sound-alarm-on malady.html?hp\&utm_source=buffer\&buffer_share=7418a\&_r=1.

Woody, Todd. "The U.S. Bans GMOs, Bee-Killing Pesticides in All Wildlife Refuges." TakePart, July 2014. http://www.takepart.com/article/2014/07/31/us-bans-gmos-bee-killingpesticides-national-wildlife-refuges.

Wright, Virginia M. "Ogunquit Leads the Way." Down East: The Magazine of Maine, November 2014. http://downeast.com/ogunquit-leads-the-way/.

Xerces. 2013. Scientists Call for an End to Cosmetic Insecticide Use After the Largest Bumble Bee Poisoning on Record. The Xerces Society for Invertebrate Conservation. http://www.xerces. org/2013/06/27/scientistscall-for-an-end-to-cosmetic-insecticide-use-after-the-largest-bumble- beepoisoning-on-record/

You can sort or clean your list in a variety of ways.

"Velasquez, Manuel, Claire Andre, Thomas Shanks, and Michael J. Myer. "Calculating Consequences: The Utilitarian Approach to Ethics." Calculating Consequences: The Utilitarian Approach to Ethics 2, no. 1 (1989). 


\section{Appendix: HR 1284}

[Congressional Bills 114th Congress]

[From the U.S. Government Printing Office]

[H.R. 1284 Introduced in House $(\mathrm{IH})]$

\section{4th CONGRESS}

1st Session

H. R. 1284

To direct the Administrator of the Environmental Protection Agency to take certain actions related to pesticides that may affect pollinators, and for other purposes. 


\title{
IN THE HOUSE OF REPRESENTATIVES
}

March 4, 2015

Mr. Conyers (for himself and Mr. Blumenauer) introduced the following bill; which was referred to the Committee on Agriculture

\begin{abstract}
A BILL
To direct the Administrator of the Environmental Protection Agency to take certain actions related to pesticides that may affect pollinators, and for other purposes.
\end{abstract}

Be it enacted by the Senate and House of Representatives of the United States of America in Congress assembled,

\section{SECTION 1. SHORT TITLE.}

This Act may be cited as the "Saving America's Pollinators Act of 2015".

\section{SEC. 2. FINDINGS.}

Congress finds the following:

(1) Pollination services are a vital part of agricultural production, valued at over $\$ 125,000,000,000$ globally. According to a 2014 Presidential memorandum, pollinators provide for an annual amount of $\$ 24,000,000,000$ to the economy of the United States and honey bees account for $\$ 15,000,000,000$ of such amount. Similarly, pollination services of native pollinators, such as bumblebees, squash bees, and mason bees, contribute over $\$ 3,000,000,000$ to the United States agricultural economy and are estimated to contribute between $\$ 937,000,000$ and $\$ 2,400,000,000$ to the economy of California alone.

(2) One-third of food produced in North America--including nearly 100 varieties of fruits and vegetables such as almonds, avocados, cranberries, and apples--depends on pollination by bees.

(3) Over the past several years, documented incidents of colony collapse disorder and other forms of excess bee mortality have been at a record high, with some beekeepers repeatedly losing 100 percent of their operations. The national honey crop reported in 2013 was the lowest in many decades. 
(4) A recent national survey sponsored by the Federal Government indicates that United States beekeepers experienced a 45.2 percent annual mortality rate with their hives during the period beginning in April 2012 and ending in March 2013. During the winter of 2013-2014, two-thirds of beekeepers experienced loss rates greater than the established acceptable winter mortality rate.

(5) According to scientists at the Department of Agriculture, current losses of honey bee colonies are too high to confidently ensure the United States will be able to meet the pollination demands for agricultural crops.

(6) Native pollinators, such as bumble bees, have also suffered alarming population declines. There are currently more than 40 pollinator species federally-listed as threatened or endangered, and most recently, the iconic monarch butterfly has declined by 90 percent.

(7) Scientists have linked the use of a certain class of systemic insecticides, known as neonicotinoids, to the rapid decline of pollinators and to the deterioration of pollinator health.

(8) Neonicotinoids cause sublethal effects, including impaired foraging and feeding behavior, disorientation, weakened immunity, delayed larval development, and increased susceptibility to viruses, diseases, and parasites. Numerous reports also document acute, lethal effects from the application of neonicotinoids.

(9) Conclusions from a recent global review of the impacts of systemic pesticides, primarily neonicotinoids, warn that they are causing significant damage to a wide range of beneficial invertebrate species, are a key factor in the decline of bees, and pose a global threat to biodiversity and ecosystem services. Another recent global review documented high levels of freshwater contamination.

(10) Science has demonstrated that a single corn kernel coated with a neonicotinoid is toxic enough to kill a songbird. Peer-reviewed research from the Netherlands has shown that the most severe bird population declines occurred in those areas where neonicotinoid pollution was highest. Starlings, tree sparrows, and swallows were among the most affected.

(11) In January 2013, the European Food Safety Authority determined that the most widely used neonicotinoids pose unacceptable hazards to bees, prompting the European Union to suspend their use on agricultural crops. 
(12) In June 2013, over 50,000 bumblebees were killed as a direct result of exposure to a neonicotinoid applied to linden trees for cosmetic purposes.

(13) In February 2014, Eugene, Oregon, voted to ban the use of neonicotinoid pesticides on city property. Similar bans and restrictions have been enacted in Thurston County, Spokane, and Seattle, Washington, and Skagway, Alaska.

(14) In June 2014, a Presidential memorandum established a Pollinator Health Task Force after identifying pollinator decline as a threat to the sustainability of food production systems, the agricultural economy, and the health of the environment in the United States.

(15) In July 2014, the United States Fish and Wildlife Service announced plans to phase out neonicotinoid pesticides in all national wildlife refuges across the United States by January 2016. The United States Fish and Wildlife Service recognized that the prophylactic use of neonicotinoids for agricultural purposes harms a wide range of non-target species and is therefore inconsistent with the management policy of the United States Fish and Wildlife Service.

(16) In October 2014, an assessment by the Environmental Protection Agency found that neonicotinoid seed coatings provide little benefit to overall soybean crop yield. Additional studies determined that in approximately 80 to 90 percent of row crop uses, neonicotinoid coatings are unnecessary. The prophylactic overuse of neonicotinoids violates the fundamental principles of integrated pest management.

(17) In November 2014, the Province of Ontario announced the province will move to restrict the use of neonicotinoidcoated corn and soybean seeds because of the broad harms from their overuse, with a goal of 80-percent reduction by 2017.

\section{SEC. 3. URGENT REGULATORY RESPONSE FOR HONEY BEE AND POLLINATOR PROTECTION.}

(a) In General.--Not later than 180 days after the date of the enactment of this Act, the Administrator of the Environmental Protection Agency shall suspend the registration of imidacloprid, clothianidin, thiamethoxam, dinotafuran, and any other members of the nitro group of neonicotinoid insecticides to the extent such insecticide is registered, conditionally or otherwise, under the Federal Insecticide, Fungicide, and Rodenticide Act (7 U.S.C. 136 et seq.) for use in seed treatment, soil application, or foliar treatment on bee-attractive plants, trees, and cereals until the Administrator has made a determination that such insecticide will not cause 
unreasonable adverse effects on pollinators based on--

(1) an evaluation of the published and peer-reviewed scientific evidence on whether the use or uses of such neonicotinoids cause unreasonable adverse effects on pollinators, including native bees, honey bees, birds, bats, and other species of beneficial insects; and

(2) a completed field study that meets the criteria required by the Administrator and evaluates residues, including residue buildup after repeated annual application, chronic lowdose exposure, cumulative effects of multiple chemical exposures, and any other protocol determined to be necessary by the Administrator to protect managed and native pollinators.

(b) Conditions on Certain Pesticides Registrations.-Notwithstanding section 3 of the Federal Insecticide, Fungicide, and Rodenticide Act (7 U.S.C. 136a), for purposes of the protection of honey bees, other pollinators, and beneficial insects, the Administrator of the Environmental Protection Agency shall not issue any new registrations, conditional or otherwise, for any seed treatment, soil application, and foliar treatment on bee-attractive plants, trees, and cereals under such Act until the Administrator has made the determination described in subsection (a), based on an evaluation described in subsection (a)(1) and a completed field study described in subsection (a)(2), with respect to such insecticide.

(c) Monitoring of Native Bees.--The Secretary of the Interior, in coordination with the Administrator of the Environmental Protection Agency, shall, for purposes of protecting and ensuring the long-term viability of native bees and other pollinators of agricultural crops, horticultural plants, wild plants, and other plants--

(1) regularly monitor the health and population status of native bees, including the status of native bees in agricultural and nonagricultural habitats and areas of ornamental plants, residential areas, and landscaped areas;

(2) identify the scope and likely causes of unusual native bee mortality; and

(3) beginning not later than 180 days after the date of the enactment of this Act and each year thereafter, submit to Congress, and make available to the public, a report on such health and population status.

$$
<\text { alls }
$$

